\title{
Toxoplasma ferlin1 is a versatile and dynamic mediator of microneme
}

\section{trafficking and secretion}

$9 \quad{ }^{1}$ Biology Department of Biology, Boston College, Chestnut Hill, MA 02467, USA

$10 \quad{ }^{2}$ Department of Molecular Microbiology and Immunology, Johns Hopkins University Bloomberg

11 School of Public Health, Baltimore, Maryland, USA

14 \$Correspondence to Marc-Jan Gubbels, gubbelsj@,bc.edu

15 †resent address: Bradley. I Coleman, Harvard Medical School, Boston, Massachusetts, USA

18 Running title: Toxoplasma ferlin 1 acts on micronemes 


\section{Abstract}

20 Calcium-dependent exocytosis of the microneme organelles that facilitate host cell invasion is

21 critical for obligate intracellular apicomplexan parasites such as Toxoplasma gondii. Ferlins

22 represent a protein family with roles in exocytosis containing multiple $\mathrm{Ca}^{2+}$-sensing $\mathrm{C} 2$ domains.

23 Here we defined the role of T. gondii's ferlin 1 (FER1) in microneme biology. FER1 localized

24 dynamically to several compartments of the parasite's secretory pathway as well as to an apical

25 spot near the site of microneme secretion. FER1 function was dissected by overexpression of a

26 variety of N-terminally tagged alleles causing dominant negative phenotypes. This demonstrated

27 FER1 traffics microneme organelles at several discrete steps of their natural trajectories: 1. from

28 ELC to the subpellicular microtubules; 2. along the subpellicular microtubules to the apical end;

29 3. into the conoid; 4. and inferred from observed retrograde transport from the subpellicular

30 microtubules, recycling of micronemes from mother to daughter parasites. Furthermore, full-

31 length FER1 overexpression results in a squirt of microneme release sufficient for host cell

32 egress. This indicates FER1 facilitates fusion of the most apical, radially organized micronemes

33 with the plasma membrane. Moreover, FER1 acts differentially on the Rab5A/C-dependent and -

34 independent microneme sub-populations. Finally, apical FER1 overlaps with the presence of

35 VP1, a pyrophosphatase proton pump. Integrating all new insights, we propose a model of

36 microneme exocytosis wherein the radial micronemes constitute a readily releasable vesicle pool

37 primed by acidification.

Keywords: exocytosis/calcium/ferlin/microneme/trafficking/Toxoplasma 


\section{Introduction}

In humans, the apicomplexan parasite Toxoplasma gondii causes birth defects, vision

44 loss, myocarditis and encephalitis. Lytic replication cycles unfolding through repetitive rounds of

45 host cell invasion, intracellular replication and host cell egress are central to the pathogenesis of

46 toxoplasmosis [1]. The micronemes in apicomplexan parasites are pivotal for successful host cell

47 invasion as they contain adhesion molecules facilitating gliding motility and host cell association

$48 \quad[2,3]$. In addition, the Toxoplasma gondii micronemes encode a pore-forming protein, PLP1, that

49 permeabilizes both the parasitophorous vacuole and host plasma membrane, which is required

50 for efficient host cell egress $[4,5]$. The parasite's signal transduction pathways controlling the

51 correct timing of micronemes secretion comprises cGMP, $\mathrm{Ca}^{2+}$ and phosphatidic acid (PA) [6],

52 accompanied by a crucial cAMP-mediated switch between the intracellular and extracellular

53 states [7].

54 The micronemes are localized along the apical cortex in association with the subpellicular

55 microtubules emanating from the apical end $[8,9]$. Upon activation of secretion, micronemes

56 move into the conoid, a tubulin basket at the very apical tip of the parasites, to fuse with the

57 plasma membrane. Following secretion, microneme protein complexes are embedded in the

58 plasma membrane with the extracellular domains serving as adhesion domains and the

59 cytoplasmic tail engaging with actin filaments that are transported in an apical to basal direction

60 by a myosin motor anchored in the membrane skeleton [10]. The working model is that

61 sustainable microneme secretion is dosed to support prolonged periods of gliding motility to

62 cross biological barriers in between host cells. Dosing is most likely achieved by gradually

63 trafficking micronemes aligned on the subpellicular microtubules toward the conoid to avoid

64 bulk micronemal content release. In addition, a set of radial micronemes organized and anchored

65 just below the conoid is believed to be a readily-releasable pool of micronemes [11-13].

Biogenesis of the micronemes and trafficking of microneme proteins progresses through

67 the secretory pathway comprising sequential passage through the endoplasmic reticulum (ER),

68 Golgi apparatus, trans-Golgi Network (TGN) and an endosome like compartment (ELC) [14-16].

69 Many secretory proteins undergo proteolytic processing to remove their pro-peptide mediated by

70 the plant like vacuole (VAC or PLV), an acidic compartment [17-20]. Protein sorting to both

71 microneme and rhoptry organelles requires sortilin (SORTLR) [21] whereas the

72 HOPS/CORVET complex and Rab7 are involved in PLV/VAC routing [22]. Moreover, adaptor 
complex AP1 is involved in microneme and rhoptry protein trafficking, but has a more general

74 function across other vesicular trafficking events [23]. Although some rhoptry specific targeting signals have been identified [24, 25], specific sorting signals for microneme proteins are still elusive. Specific Rab GTPases have been associated with some aspects of microneme protein trafficking, and actually differentiate two sub-populations of micronemes with a different protein content: one of which is Rab5A/C-dependent, and one that is Rab5A/C-independent [9]. Consequently, specific microneme proteins end up in different, non-overlapping microneme subpopulations. The exocytosis event at the very apical tip has been associated with Centrin2 [26] and double $\mathrm{C} 2$ (TgDOC2) [27], both of which are $\mathrm{Ca}^{2+}$-binding proteins. Furthermore, the association of an acylated pleckstrin homology (PH) domain-containing protein (APH) on the surface of the micronemes with PA deposited in the plasma membrane is essential for exocytosis and aid in timing membrane fusion [28]. In addition, Rab11a is present at the very apical end of the parasite and is required for efficient microneme exocytosis, though Rab11a's function is not exclusively acting on the micronemes and is much more varied [29]. The proposed membrane fusion model comprises v- and t-SNAREs on the microneme limiting membrane and the plasma membrane, respectively, where TgDOC2, mediates the $\mathrm{Ca}^{2+}$ regulation, which together with Rab11a and the APH-PA interaction pull the membranes together toward their fusion [6, 30]. However, the identity of such SNAREs is still elusive. Finally, sustained microneme secretion in extracellular parasites is balanced with active endocytosis [31], whereas during cell division micronemes of the mother are re-directed into the newly forming daughters [32].

In all the well-studied $\mathrm{Ca}^{2+}$ triggered exocytosis systems, proteins containing double $\mathrm{C} 2$,

94 (DOC2) domains execute the $\mathrm{Ca}^{2+}$-mediated vesicle fusion [33]. C2 domains are approximately

95150 amino acids in length and composed of eight beta strands that insert into a membrane or

96 associate with other proteins, some of which are conditional upon the presence of $\mathrm{Ca}^{2+}[33,34]$.

97 Binding of $\mathrm{Ca}^{2+}$ and/or phospholipids is facilitated by specifically positioned residues in three

98 loops extending from the $\mathrm{C} 2$ domain. Aspartate residues, and to some extent glutamate, create a 99 negatively charged binding pocket that permits $\mathrm{Ca}^{2+}$ binding [35-37]. The binding of $\mathrm{Ca}^{2+}$ leads

100 to conformational changes facilitating insertion into a membrane or lipid binding via a calcium

101 bridge $[38,39]$. Alternatively, asparagine in these positions, eliminates the negative charge, and 102 promotes phospholipid binding independent of $\mathrm{Ca}^{2+}[36,37]$. Typically, at least one membrane 103 associated and one soluble DOC2 protein are needed to facilitate $\mathrm{Ca}^{2+}$-dependent fusion. We 
104 have previously identified a soluble TgDOC2 protein essential for Toxoplasma microneme

105 secretion [27]. The ferlins make up a unique branch of the DOC2 domain protein family because

106 they are relatively large $(200-240 \mathrm{kDa})$ and contain five to seven $\mathrm{C} 2$ domains rather than two,

107 which are typically organized in C2 pairs to form 2-3 DOC2 domains. The extended C2

108 repertoire in ferlins has broadened their functional spectrum beyond membrane fusion to vesicle

109 trafficking and membrane repair [40]. Mammalian ferlins come in two flavors differentiated by

110 their sub-cellular localization at either the plasma membrane or on intracellular compartments,

111 which relates to their function in either late endosomal transit versus trans-Golgi recycling [41].

112 Mammalian otoferlin, essential for neurotransmitter release from the inner hair cells (IHC) in the

113 auditory system, has been most widely studied. Otoferlin functions as both a scaffolding protein

114 in the secretory pathway as well as in the actual membrane fusion during exocytosis [42-45].

115 The Apicomplexa encode two conserved ferlin proteins, FER1 and FER2, but some

116 parasites, including $T$. gondii, encode a degenerate third ferlin [46]. FER1 in Plasmodium

117 berghei, named ferlin-like protein (PbFLP), was recently reported to be essential for male

118 gametocyte egress [47], whereas we showed that Toxoplasma FER2 is required for rhoptry

119 secretion [46]. Here we examined the function of FER1 in microneme protein trafficking,

120 microneme dynamics and secretion in the Toxoplasma gondii lytic cycle.

123 Results

124 1. Toxoplasma FER1 localizes to the secretory pathway and a discrete apical region

125 In the genome wide fitness screen for the Toxoplasma lytic cycle FER1 (TGGT1_309420) has a 126 severe fitness score of -4.77 , strongly indicating that this protein is essential [48]. The critical

127 role of FER1 in the lytic cycle was underscored in our unsuccessful efforts to generate either an

128 endogenously tagged allele at either the $\mathrm{N}$ - or C-terminus to determine its sub-cellular

129 localization. Since FER1 is a tail-anchored transmembrane (TM) domain containing protein

130 ([49], Fig 1A), we reasoned that we could resolve its subcellular localization through fusion of

131 the terminal transmembrane (TM) domain including the extreme C-terminal cytoplasmic tail to a

132 YFP reporter. Transient transfection of parasites with an $\alpha$-tubulin promoter driven fusion

133 construct encoding the C-terminal 31 aa (comprising the 10 aa before the extreme C-terminal and

134 the 21 aa long TM domain) resulted in YFP signal in an extremely apical, conoid-associated 
135 region as well as in the perinuclear region (Fig 1B). This indicates that FER1 localizes to the

136 endoplasmic reticulum surrounding the nucleus as well as to the very apical tip of the parasite

137 from where microneme and rhoptry organelle exocytosis takes place. To corroborate these data,

138 we generated a polyclonal antiserum against the central C2DE domain (Fig 1A), which is the

139 most evolutionary diverse sequence of the protein compared to the other ferlins encoded by

140 Toxoplasma. By western blot, the affinity purified antiserum reacts with the full-length FER1

141 protein with a predicted molecular weight of $159 \mathrm{kDa}$. In addition, additional bands at

142 approximately 120 and $30 \mathrm{kDa}$ were detected. These bands most likely represent fragments of

143 the full length FER1 protein, although cross reactivity with other proteins cannot be excluded.

144 However, the localization pattern of the $\alpha$-FER1 serum by IFA resembles the pattern seen with

145 the YFP fusion to the TM domain of FER1, which suggests high specificity for FER1 in IFA

146 (Fig 1D,E). Again, we observe a very apical spot next to a perinuclear signal. To assess whether

147 the perinuclear localization extends beyond the ER we co-stained parasites with dynamin related

148 protein $\mathrm{B}(\mathrm{DrpB})$, a marker for the endosome like compartment (ELC) [50]. The ELC is a

149 structure in the secretory pathway past the Golgi apparatus and Trans Golgi Network (TGN) and

150 DrpB is critical for directing microneme and rhoptry proteins to their final destination [50].

151 Although direct co-staining is weak, the DrpB signal is seen right next to intense FER1 foci (Fig

152 1D), which suggests they could mark different compartments in the ELC. Together with the

153 continuous perinuclear stain these data indicate that FER1 distributes to the whole secretory

154 pathway including the Golgi apparatus. To elucidate the extreme apical regions to which FER1

155 localizes we co-stained parasites with antiserum against Vacuole Protein 1 (VP1). VP1 marks the

156 plant like vacuole (PLV) and acidocalcisomes in Toxoplasma, but an unspecified apical signal

157 near the conoid is also consistently observed [50-54]. We observe direct co-stain of FER1 and

158 VP1 in the apical tip of the parasite (Fig 1E). Finally, we co-stained extracellular parasites with

159 MIC2 antiserum to highlight the micronemes (Fig 1F). FER1 and MIC2 signals were physically

160 distinct, with FER1 more apical than MIC2 in the micronemes. In extracellular parasites, the

161 FER1 signal was more exclusively localizing apical of the nucleus, suggestive of the Golgi, TGN

162 or ELC, contrasting with the peri-nuclear FER1 signal in intracellular parasites and suggesting a

163 dynamic pattern for FER1. Taken together, FER1 localization at the apical VP1 compartment of

164 unknown identity is seen in both intra- and extra-cellular parasites, whereas FER1 marks the

165 entire ER to ELC pathway in intracellular parasites but is absent from the ER in extracellular 
166

167

168

169

170

171

172

173

174

175

176

177

178

179

180

181

182

183

184

185

186

187

188

189

190

191

192

193

194

195

196

parasites. FER1's localization pattern in $T$. gondii is consistent with mammalian ferlins functioning in late endosomal transit versus TGN recycling [41], since trafficking to the rhoptries and micronemes in the Apicomplexa is facilitated by a modified endosomal system $[15,16]$.

\section{Generation and validation of conditionally lethal FER1 mutant lines}

To dissect the function of FER1 we followed a dominant negative (DN) approach. We anticipated that conditional overexpression of an allele without the C-terminal TM domain would mislocalize FER1, divert its interacting proteins, and disrupt its function. We generated an $\alpha-$ tubulin promoter driven N-terminal fusion of the destabilization domain (DD) linked to a Myc epitope that can be conditionally stabilized with Shield-1 [55]. We designed both an allele without the $21 \mathrm{C}$-terminal amino acids encoding the TM domain (DD-Myc-FER1 $\Delta \mathrm{TM}$ ) as well as a control construct encoding the full-length FER1 protein (DD-Myc-FER1 ${ }^{\mathrm{FL}}$ ) (Fig 2A). We were able to generate stable parasite lines with both constructs in absence of Shield-1. Expression of the full-length proteins was assessed by western blot, showing higher FER1 levels already in the absence of Shield-1 as the lower MW bands seen in wild type parasites were not observed at the exposure time needed to detect the overexpressed protein (Fig 1C, 2B). Next, we showed by plaque assay that overexpression of both the $\Delta \mathrm{TM}$ and FL alleles caused a severe fitness defect (Fig 2C). These observations underscore a critical role of FER1 in the lytic cycle as seen in the genome wide CRISPR screen [48].

\section{FER1 $\triangle$ TM overexpression causes a microneme secretion defect}

To globally determine the cause of the lethal defect upon FER1 $\Delta$ TM overexpression we evaluated the following key events of the lytic cycle: host cell invasion (Fig 3A), replication (Fig 3B,C), and host cell egress (Fig 3D-F). Host cell invasion was strongly reduced, consistent with an anticipated FER1 role in invasion through microneme content exocytosis. We observed a mild reduction in the parasite multiplication rate, with a slight but significant $(p=0.031)$ accumulation of parasites in the 4-cells/vacuole stage compared to the controls (Fig 3B). We did not detect a specific delay in a particular cell cycle stage (Fig 3C), suggesting that the overall rate through cell division is somewhat reduced. As summarized in Fig 3D, we triggered egress by several different secretagogues, engaging the signaling pathway toward egress at different points: most upstream is zaprinast to activate protein kinase $\mathrm{G}(\mathrm{PKG})$, followed by ethanol activating 
197 phosphoinositide phospholipase C (PI-PLC) right before the bifurcation in a $\mathrm{Ca}^{2+}$-dependent

198 (triggered with $\mathrm{Ca}^{2+}$-ionophore A23187) and phosphatidic acid (PA) dependent pathway

199 (triggered with phosphatidic acid phosphatase (PAP) inhibitor propranolol) [28]. We monitored

200 egress by assessing the integrity of the parasitophorous vacuole membrane (PVM) using GRA3

201 as PVM marker and the parasite's cytoskeleton marker IMC3 for parasite dispersal in the

202 environment (Fig 3F). None of these secretagogues efficiently induced egress (Fig 3E). To

203 determine whether the defect was specific to egress as observed in CDPK3 signaling mutants

204 [56-58], we permeabilized the plasma membrane with saponin. This bypasses the signaling step

205 specific for egress and triggers the activation of motility by the extracellular environment.

206 Although this did not trigger egress in the FER1 $\triangle$ TM overexpressing mutant, we noticed loss of

207 PVM integrity upon overexpression. Even though saponin might contribute to this effect, this

208 observation is suggestive of modest microneme release. We performed trail assays as a

209 functional and independent assay to assess microneme secretion, and determined that it is

210 insufficient to support gliding (Fig 3G). Finally, we determined differential microneme secretion

211 from the Rab5A/C-dependent (MIC3, 5, 8) and -independent (MIC2, MIC10, M2AP, PLP1, etc.)

212 microneme sub-populations [9]. The former sub-population was tested by release of processed

213 MIC2 in the medium under various exocytosis triggering conditions, whereas the latter was

214 visualized by MIC3, 5 and 8 protein exposure on the parasite's surface. Overall, we see a sharp

215 reduction in secretion from both microneme populations in the FER1 $\triangle$ TM overexpressing

216 mutant to nearly undetectable levels. However, we reproducibly detected propranolol induced

217 secretion at a 10-fold lower level than in the non-induced control (a drop from 161\% to 15\%

218 relative to the total $10 \%$ total microneme control; Fig $3 \mathrm{H}$ ). In addition, we observed a very small

219 amount of MIC3 on the surface of induced parasites, indicating that this population still has

220 minor secretion capacity as well (Fig 3I). Since propranolol triggers the PA pathway, which is

221 independent of the $\mathrm{Ca}^{2+}$-dependent leg (Fig 3D), this section of the pathway appears to be still

222 functioning, albeit at a very low level. Taken together, this suggests that FER1 acts primarily in

223 the $\mathrm{Ca}^{2+}$-dependent events in the micronemal secretory pathway.

\section{4. FER1 $\Delta$ TM overexpression causes a microneme trafficking defect}

226 By design, we anticipated that FER1 $\Delta$ TM would mislocalize. Using the Myc-tag in the

227 overexpression DD-Myc-FER1 $\Delta$ TM construct in IFA revealed a striking accumulate in a defined 
mid-apical region, within a background of lower intensity Myc dispersed throughout the cytoplasm also seen in absence of Shield-1 (Fig 4A). We reasoned that the background Myc signal is likely due to proteasome degraded fragments present throughout the cytoplasm. We addressed this concern by overexpressing a YFP version since YFP fragments generated by the

232 proteasome would not autofluorescence. Indeed, we observe no YFP signal without Shield-1

233 whereas under Shield-1 we see a similar signal in the mid-apical region as seen with the Myc-

234 tagged version. Therefore, we used the YFP version for all subsequent imaging experiments. Co-

235 staining with several microneme proteins in the Rab5A/C-dependent (MIC5 stained) and -

236 independent (MIC2 stained) class showed perfect overlap with the accumulated YFP signal

237 suggesting all microneme proteins are misdirected (Fig 4B,C, S2A,B). The FER1 antiserum

238 signal also co-localizes with the YFP signal. This could suggest that endogenous FER1 may also

239 be diverted from its apical tip and peri-nuclear enrichments to the accumulation of dominant

240 negative FER1

241 overexpressed FER1 $\triangle \mathrm{TM}$ as seen by western blot (Fig 2B) overwhelms the endogenous signal.

242 Collectively, these data indicate that both the Rab5A/C dependent and independent microneme

243 sub-populations are controlled by FER1. Since all known microneme protein trafficking mutants

244 in the endosomal sections have concurrent defects in rhoptry protein trafficking [18], we

245 interrogated the rhoptries by IFA. We observed that the ROP proteins remained localized to

246 rhoptries, and that the rhoptries displayed their normal morphology and distribution (Fig 4E).

247 This striking distinction makes the DN-FER1 phenotype a first of its kind for the unique

248 disruption of microneme trafficking while leaving the rhoptries intact.

249 The central apical localization is reminiscent of the position of various compartments of

250 the Toxoplasma secretory pathway. To differentiate whether the accumulation is due to an arrest

251 in trafficking, mis-trafficking, or is of another nature we used a series of secretory pathway

252 specific compartment markers in co-localization experiments (Fig 4F, G). First, we checked

253 whether the FER1 co-localization with PLV/VAC compartment using VP1 as marker. We

254 observe no overlap at all between the VP1 and YFP signals (Fig 4F). We observed similar lack

255 of co-localization with PLV/VAC compartment using NHE3 as an independent marker of this

256 compartment [54] and show that it still displays its normal morphology (Fig S2C). However, we

257 noted that the VP1 signal at the apical end is still very prominent (Fig 4F). Surprisingly, we

258 never observed co-localization of the mid-apical DD-YFP-FER1 1 TM signal with the Golgi 
apparatus, TGN, or the ELC, which all displayed their normal morphology. Instead, DD-YFPFER1 $\triangle \mathrm{TM}$ accumulated in a uncharacterized compartment, beyond any of the known trafficking steps toward the micronemes, and after the split from rhoptry protein trafficking [18].

To reveal the sites of DD-YFP-FER1 $\Delta \mathrm{TM}$ and microneme protein accumulation, we performed transmission electron microscopy (Fig 4H-M). EM studies illustrate that in DD-YFPFER1 1 TM-expressing parasites, micronemes with normal ultrastructure were not decorating the cytoplasmic side of the cortical cytoskeleton at the apical end but instead were aggregated in the cytoplasm at the apical region of the parasite (Fig 4H). In addition, we observed electron-lucent compartments that in several cases contained electron-dense material (Fig 4I, J). We further investigated the content of these enlarged compartments with possible microneme connection by immunolabeling the parasites with $\alpha$-MIC2 antibody. Gold particles positioned MIC2 in the aggregated microneme structures (Fig 4K) as well as on the outside edges of the electron-lucent compartments and within the electron-dense spheres within the electron-lucent compartments

272 (Fig 4L,M). The MIC2 association and the appearance of electron dense structures is consistent

273 with the function shared between the ELC and PLV/VAC compartments previously reported [17,

274 59]. Although these compartments appear enlarged, they are likely part of the physiological

275 trafficking pathways of microneme proteins. In summary, overexpression of dominant negative

276 FER1 $\Delta$ TM leads to mislocalization of fully mature micronemes without disrupting the

277 trafficking pathway or the biogenesis of the rhoptries. These data indicate that FER1 functions in

278 the trafficking and/or biogenesis of micronemes beyond the ELC, which is the least understood

279 step in microneme biogenesis and secretion [14].

\section{DD-YFP-FER1 $\triangle T M$ overexpression retracts micronemes from the periphery}

282 We tested whether the aggregated micronemes in the mid apical region observed by EM did 283 complete their biogenesis by staining with a marker present on mature micronemes: acylated 284 pleckstrin-homology $(\mathrm{PH})$ domain-containing protein (APH). APH on the microneme's surface 285 senses PA during microneme secretion and is necessary for microneme exocytosis [28]. Indeed, 286 APH co-localized with the site of FER1 accumulation in both intra- and extra-cellular parasites

287 which indicates that the mis-localized micronemes, for signaling purposes, are primed for 288 secretion as in non-induced parasites (Fig 5A). In addition, in extracellular parasites we 289 frequently observed a specific APH signal at the very apical end of the parasite (arrowhead in 
Fig 5A). These likely represent a small microneme population that can still be secreted, consistent with the $10 \%$ residual microneme secretion in induced parasites (Fig $3 \mathrm{H}, \mathrm{I})$. In addition, as guided by the EM data, we asked whether the microneme proteins are fully matured, i.e. completed proteolytic processing by removal of the pro-peptide in the ELC/VAC compartment $[17,20]$. We used specific antisera against the pro-peptide of M2AP together with antiserum reacting with the mature M2AP protein [60]. By western blot we observe no difference in relative abundance of the pro-M2AP protein versus the total amount of M2AP protein across all conditions and mutants tested (Fig 5B). Furthermore, by IFA we observe normal MIC5 pro-peptide containing proteins in the ELC compartment [60], and no colocalization with the FER1 accumulation (Fig 5C). These observations further support that the mislocalized micronemes contain mature proteins that completed processing through the secretory pathway.

Since pro-MIC5 manifests predominantly in budding parasites, the co-staining with FER1 revealed another intriguing phenomenon: there appeared to be no DD-YFP-FER1 $\triangle T M$ accumulation in newly forming parasites. We validated this model by a triple staining with YFP, $\alpha$-pro-MIC5 and daughter bud marker $\alpha$-IMC3 (Fig 5D). Moreover, representative images through the division cycle demonstrate that the YFP migrates basally toward the residual body in parasites undergoing division (Fig 5E). Moreover, we never observed any new micronemes in the apical peripherally of daughter buds either (Fig 5F). Collectively, these data indicate that microneme pro-protein processing by the ELC/VAC compartment progresses normally in newly

311 proteins end up in the YFP-FER1 $\triangle \mathrm{TM}$ pile up formed in the mother. This raised the next

312 intriguing question: is the YFP aggregation independent of cell division? This model implies that 313 normally localized micronemes can be retracted from the periphery and directed toward the YFP

314 microneme aggregate. To this end we performed time courses to determine induction and

315 reversion kinetics of the Shield-1 induced phenotype in both intracellular and extracellular

316 parasites. Microneme mis-localization kinetics were over 95\% complete within three hours (Fig

$3175 \mathrm{G}$ top panel). This time frame is much smaller than the $6.5 \mathrm{hr}$ cell division cycle, indicating that

318 the process is not cell cycle dependent as in an unsynchronized population typically $30 \%$ of the

319 parasites is undergoing daughter budding [61]. The exact same kinetics were also observed in

320 extracellular parasites which are arrested in a non-division G1/0 state (Fig 5G bottom panel). 
321 What was even more striking is that the phenotype is completely reversible with kinetics very

322 comparator to induction (Fig 5G). Finally, to directly visualize the cell division independent re-

323 localization of the micronemes we performed time lapse microscopy following Shield-1

324 induction. In DD-YFP-FER1 $\triangle$ TM co-expressing a MIC3-mCherryRFP marker we observed that

325 microneme retraction and accumulation with YFP-FER1 $\Delta$ TM started after $1.5 \mathrm{hr}$ of Shield-1

326 induction (Supplementary Movie S1 and Fig 5H). Moreover, time lapse imaging confirmed that

327 microneme retraction was independent of daughter budding as tracked with a marker enriched in

328 daughter cytoskeletons, IMC3-mCherryRFP (Supplementary Movie S2 and Fig S3). Taken

329 together, overexpression of a dominant negative FER1 allele induces retraction of already

330 correctly localized micronemes from the periphery toward a centrally localized organelle

331 accumulation regardless of cell division cycle stage. The reversible nature of the FER1 mediated

332 process indicates that whole organelle microneme trafficking in principle is bidirectional from

333 where they are docked on the subpellicular micronemes to the site of apical aggregation beyond

334 the known secretory pathway compartments. Therefore, our data reveal that microneme

335 trafficking can in principle be bidirectional and might not be exclusively targeted toward the

336 apical end in support of exocytosis.

\section{FER1 ${ }^{\mathrm{FL}}$ overexpression results in premature, untriggered microneme secretion}

339 The precarious nature of FER1 function was evident from the lethal effect of DD-Myc-FER1 $1^{\mathrm{FL}}$

340 overexpression (Fig 2C). We dissected this phenotype first by assessing the localization of

341 FER1, which is largely unchanged upon Shield-1 induction and presents on membrane structures

342 throughout the parasite. (Fig 6A). Next, we asked whether these parasites display changes in

343 their microneme secretion ability using the set of secretagogues applied to the $\Delta \mathrm{TM}$ mutant. We

344 observe strong exocytosis under all conditions, compared to the negative DMSO control (Fig

$3456 \mathrm{~B})$. Although we see slight variations in the sensitivity to different secretagogues compared to

346 the non-induced and wild type parasites (Fig S1), they were not significant and unlikely

347 responsible for the lethal phenotype.

348 Next, we focused on microneme localization and morphology by IFA. We first assessed

349 the Rab5A/C-dependent sub-population using MIC5 and MIC8 as representatives. In non-

350 induced parasites these display the typical microneme pattern. Upon full-length FER1

351 overexpression, a dissociation of Rab5A/C-dependent microneme sub-population from the 
352 subpellicular microtubule was observed, but the most apical microneme localization remained

353 (Fig 6C). Staining for the Rab5A/C-independent population with MIC2 again revealed a change

354 in localization pattern, but this was dramatically different from the MIC8 population. By super-

355 resolution SIM, in induced intracellular parasites the microneme signal was strongly

356 concentrated at the apical end, unlike the tapering signal observed in wild type and non-induced

357 controls (Fig 6D top panels). These extremely apical micronemes, also maintained for the

$358 \mathrm{Rab} 5 \mathrm{~A} / \mathrm{C}$-dependent population, are reminiscent of the radial micronemes organized just below

359 the conoid [12]. The radial micronemes are anchored firmly in the apical region and believed to

360 be primed for secretion [11]. In extracellular parasites however, we did not notice dramatic

361 changes between the induced mutant and the controls: under all conditions MIC2 was more

362 shifted apically compared to the intracellular wild type distribution, yet not so radically apical as

363 in the intracellular induced mutant parasites (Fig 6D lower panels). To obtain an even higher

364 resolution visual on the micronemes in this mutant we resorted to both IEM and TEM. Here we

365 observe an accumulation of micronemes at the apical end, confirming the apical MIC signals

366 seen by light microscopy (Fig 6E, F). Several micronemes were squeezed inside the conoid,

367 whereas the densely packed micronemes in the apical region just below the conoid often

368 displayed an elongated morphology. Further below, we do see scattered micronemes, which

369 likely were the MIC8 micronemes as observed by IFA. Thus, it appears overexpression of N-

370 terminally tagged, full-length FER1 has a differential effect depending on the population of

371 micronemes set apart by Rab5A/C dependence: the MIC2 population is driven to the apical end,

372 whereas the MIC8 population becomes more scattered. Taken together, this is suggestive of a

373 role for FER1 in directing micronemes along the subpellicular microtubules toward the conoid.

374 To gain further insights in this phenotype we tested specific functional capacities of these

375 apically concentrated micronemes. We first showed that swift parasite egress could be triggered

376 by Shield-1 addition alone (Fig 6I). Egress implies microneme secretion, which we subsequently

377 tested under intracellular conditions in Endo buffer [62]. Release of MIC2, albeit weakly, was

378 observed upon Shield-1 induced egress (Fig 6J). However, we never observed robust levels of

379 MIC2 release, suggesting that only a small pool of micronemes can be released immediately

380 upon Shield-1 treatment. However, already a small amount of micronemal protein release could

381 lead to parasitophorous vacuole membrane permeabilization due to the action of perforin like

382 protein 1 (PLP1) secreted from the micronemes [4]. To further test the FER1 mediated 
microneme release capacity independent of other signaling triggers we tested whether egress could be triggered in small vacuoles, which have not yet established an acidified PVM [5] or accumulated secreted diacylglycerol kinase 2 (DGK2) inside the PV [63], both of which are required for natural egress [6]. To this end we modified the standard red-green invasion assay into an invasion+egress assay exploiting the same differential staining of intracellular vs extracellular parasites [64]. Following $1 \mathrm{hr}$ standard invasion, non-invaded parasites were washed away and Shield-1 added for two hrs (Fig 6K top). Nearly 50\% of vacuoles with single parasites have egressed (Fig 6K bottom), which largely mimics the $60 \%$ egress rate seen after 2 hrs of induction from large vacuoles. Collectively, these data strongly support that Shield-1

392 induced microneme secretion is only due to FER1 and not due to activation of the generic

393 signaling pathways leading to egress.

\section{Putative $\mathrm{Ca}^{2+}$-binding residues are critical for FER1 function}

396 To probe the mechanism of FER1 beyond the TM domain we analyzed the individual C2

397 domains for their functional potential. C2 domains fold into $\beta$-sheets connected by three loops

398 that can bind to proteins or insert in membranes, which can be modulated upon binding $\mathrm{Ca}^{2+}[33$,

$39934,38,39]$. Five key residues in the loops, of which the three central ones carry most weight

400 [37], can predict an association with phospholipids in membranes or $\mathrm{Ca}^{2+}$. Across the C2

401 domains in FER1, we only detected $\mathrm{Ca}^{2+}$-binding potential in the $\mathrm{C} 2 \mathrm{D}$ domain which carries

402 three Asp residues and a supportive Glu residue in the conserved loop positions which

403 potentially can stabilize two $\mathrm{Ca}^{2+}$ ions (Fig 7A,B). We tested the contribution of the C2D domain

404 to FER1 function by mutating two of the conserved Asp residues in loop 1 to Ala, which is

405 predicted to disrupt binding both $\mathrm{Ca}^{2+}$ ions (Fig 7B). We conditionally overexpressed the mutant

406 FER1 allele carrying the D541A and D545A mutations in the same N-terminal DD fusion

407 context of a $\triangle \mathrm{TM}$ or full-length allele. We were unable to express either alleles stably within

408 parasites, even in absence of Shield-1, which indicates that these C2D residues are very critical

409 to FER1 function. Instead we performed transient transfections to analyze the consequences of

410 these mutant alleles on the parasite (Fig 7C, D). Expression levels of the transgenes under

411 Shield-1 were high as vacuoles positive for both Myc and $\alpha$-FER1 staining clearly stand out in

412 both channels. However, in Myc negative vacuoles the endogenous FER1 was not discernable

413 under the settings used to optimally display the FER1 signal in overexpressing parasites, 
414 indicating that expression of the mutant allele is well above endogenous FER1 levels. Most

415 notable however, the aggregated FER1 signal was not seen upon overexpression of the wild type

416 FER1 $\triangle T M$ allele, indicating that the C2D domain is critical in mediating this phenotype.

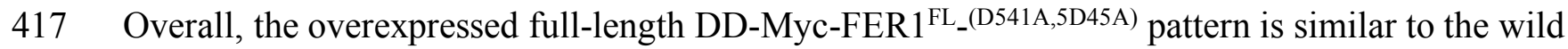
418 type allele and localizes to various focal membrane structures.

419 Subsequently, we used representative antisera to assess both the Rab5A/C-dependent

420 (MIC8) and -independent (MIC2) microneme sub-populations by IFA. For the DD-Myc-

421 FER1 $\Delta \mathrm{TM}^{(\mathrm{D} 541 \mathrm{~A}, \mathrm{D} 545 \mathrm{~A})}$ a difference between the two microneme sub-populations was noticeable:

422 the morphology and intensity of the Rab5A/C independent micronemes were indiscernible in 423 non-transfected parasites (MIC2; yellow circle in Fig 7C). However, the Rab5A/C-dependent 424 micronemes became apically defined and strongly concentrated (MIC8; white circle in Fig 7C).

425 This presentation strongly mimics the pattern seen for overexpression of the full-length wild type 426 allele (Fig 6C). Thus, it appears that the Rab5A/C-dependent micronemes do not need a

427 functional FER1's C2D domain to traffic to the apical conoid region upon FER1 overexpression.

In DD-Myc-FER1 ${ }^{\mathrm{FL}-(\mathrm{D} 541 \mathrm{~A}, \mathrm{D} 545 \mathrm{~A})}$ overexpressing parasites we do not observe a difference

429 between the microneme sub-populations by IFA. Interestingly, both microneme populations lose 430 their staining intensity compared to wild type parasites (Fig 7D, white circles). Collectively, this

431 indicates that the conferred function of domains in FER1 can change upon the context of the 432 whole proteins, e.g. by certain domains being present or absent (e.g. TM domain), accessible 433 (e.g. N-terminal fusion) or functional $\left(\mathrm{Ca}^{2+}\right.$-binding).

437 Our findings and insights are summarized in Fig 8 and support several roles for FER1 in the lytic 438 cycle, 1. Microneme protein trafficking between the ELC to the subpellicular microtubules; 2.

439 Directing the micronemes assembled on the subpellicular microtubules forward to the apical end 440 in extracellular parasites; 3. Transport into the conoid and membrane fusion between the 441 microneme and plasma membranes to facilitate exocytosis; 4. From the bi-directional and 442 completely reversible transport of the micronemes from the subpellicular microtubules to a 443 luminal position we infer that the functional relevance of this feature resides in the recently 444 reported microneme recycling from the mother parasite in daughters under assembly [32]. The 
445 dual localization pattern of endogenous FER1 (Fig 1) together with reports on the connection 446 between localization pattern and human ferlins [41] are consistent with these roles: FER1 in the

447 TGN/ELC is responsible for trafficking to (and from) the anchoring site on the subpellicular

448 microtubules, whereas FER1 in the apical end co-localizing with VP1 facilitates fusion with the

449 plasma membrane. Consistent with the tail-anchored transmembrane model [49, 65], just the TM

450 domain fused to a reporter mimics endogenous FER1 localization. Together with the mis-

451 localizing microneme phenotype upon overexpression of the $\Delta \mathrm{TM}$ allele, we assert that the TM

452 domain is associated with microneme organelle trafficking. Further support for this interpretation

453 is provided by the vesicular localization in the gametocyte cytoplasm reported for the FER1

454 ortholog PbFLP in P. berghei [47].

455 The kinetics of microneme mislocalization upon overexpression of the DN $\Delta \mathrm{TM}$ allele

456 provided additional tantalizing insights. Our extensive marker set together with the ultrastructure

457 established beyond a doubt that the aggregated micronemes are fully mature and contain fully

458 processed proteins. Most importantly, we show that completely mature micronemes at any point

459 in the cell cycle in intracellular parasites as well as in extracellular parasites are released from the

460 subpellicular microtubules and traffic back to a cytoplasmic location apical of known secretory

461 pathway compartments where they aggregate. Although similar appearing microneme pile ups

462 were recently reported upon the disruption of the vacuolar-proton ATPase (v-ATPases) in

463 Toxoplasma, they contained microneme proteins from which the pro-peptide had not been

464 cleaved [20] and thus do not represent mature micronemes like we observed. However, these

465 data support the notion that microneme morphology appears to be complete before they traffic

466 toward the subpellicular microtubules. Indeed, trafficking of micronemes from mother to

467 daughters was recently reported as well [32], which further supports the feasibility and a

468 biological function for the retrograde microneme organelle transport we observe. Moreover, the

469 effect we see is specific for the micronemes, unlike most other mutants in the endosomal legs of

470 microneme trafficking, which invariable also affect rhoptry protein trafficking (e.g. [21, 23]).

471 Overall, FER1 provides the first mechanistic insight in the microneme specific trafficking after

472 the trafficking pathway diverges from the upstream route shared with the rhoptries.

473 Overexpression of the full-length FER1 supports a direct role in membrane fusion in the

474 actual exocytosis. The first piece of evidence is that Shield-1 induction leads to fast egress of

475 parasites in vacuoles (Fig 6I,K). This invariably requires microneme secretion, and we directly 
476 detect microneme secretion, albeit modest, under intracellular conditions (Fig 6J). This modest

477 release is sufficient to drive egress, but secretion is not sustained, which requires activation of

478 the complete signaling pathway of secreted micronemes (Fig 6B). Thus excess FER1

479 compensates for other requirements for membrane fusion, such as APH engagement with PA in

480 the plasma membrane [30]. In parallel to other secretory systems [66, 67], we believe that only

481 the primed or so-called readily-releasable microneme pool is released in this mutant, but that

482 additional secretion requires renewed priming (e.g. $\mathrm{Ca}^{2+}$-dependent events such as potential

483 phosphorylation of FER1 [68]), which only occurs when the complete signaling cascade is

484 engaged. The so-called radial micronemes which are accumulated right below the conoid make a

485 good candidate for this readily releasable microneme pool $[12,13]$. The radial micronemes are

486 tightly anchored as they were the only set of micronemes remaining upon VPS9 knock-down

487 [11]. However, technically we cannot exclude that only one or two micronemes are present as

488 pre-docked micronemes at the plasma membrane and are engaged to complete fusion with the

489 plasma membrane upon FER1 overexpression.

An additional phenomenon observed upon FER1 overexpression is that the MIC2

491 microneme population squeezes into the apical end of the parasite, indicating transport was

492 triggered as well. A similar microneme apical migration phenotype was observed upon knock out

493 of the clathrin adaptor protein AP1, although that was not unique to the micronemes and acted

494 much more widely across many aspects of vesicular trafficking, including cell division [23]. But

495 it indicates that FER1 and AP1 both act in the same pathway that facilitates movement of some

496 micronemes to the apical end of the parasite. Since the AP1 mutant did not lead to microneme

497 secretion, we conclude that the short secretion burst, and apical movement are independent

498 events facilitated by FER1 overexpression. Phenomenologically, we interpret the apical

499 movement as part of the process of secretory vesicle replenishment. By comparison, in mammals

500 a role for otoferlin in replenishment of synaptic vesicles is supported, which mimics this

501 particular function of FER1 in Toxoplasma [13, 45, 69].

502 Our data on FER1 indicate that the TM domains is needed to anchor FER1 in early

503 segments of the secretory pathway (ER, Golgi, TGN, ELC). C2 domain analysis of FER1 only

504 pointed at C2D with potential for $\mathrm{Ca}^{2+}$ binding and no strong indicators of potential phospholipid

505 binding were identified. Among mammalian ferlins, the C2D domain of otoferlin has been

506 demonstrated directly to bind $\mathrm{Ca}^{2+}$ [42] and interacts with MyosinVI [70] to enable vesicle 
507 transport [43]. In general, low $\mathrm{Ca}^{2+}$ promotes intramolecular protein-protein interactions among 508 otoferlin C2C, C2D, C2E, and C2F domains, whereas high $\mathrm{Ca}^{2+}$ triggers a conformational switch 509 and leads to interaction with phospholipids [43] and SNARE proteins in vitro [71, 72].

510 Translated onto Toxoplasma FER1, these observations and our analysis suggest that the C2 511 domains function in intra-molecular protein-protein interactions to expose or hide functional 512 domains conditional upon signaling conditions. Indeed, depending on the FER1 mutant used, we 513 observe distinct effects on the Rab5A/C-dependent and -independent microneme populations.

514 For example, upon full-length overexpression we observe the Rab5A/C-independent micronemes 515 (MIC2) moving forward without a notable change in the Rab5A/C-dependent micronemes 516 (MIC5/8), whereas without the TM, the $\mathrm{C} 2 \mathrm{D} \mathrm{Ca}^{2+}$-binding sites are needed to drive the MIC5/8 517 micronemes apically, suggesting the TM acts differentially on these microneme subsets. The

$518 \mathrm{C} 2 \mathrm{D} \mathrm{Ca}^{2+}$-binding sites promote apical microneme migration along the subpellicular

519 microtubules. In addition, an intact C2D domain is needed to either maintain or form the MIC2 520 micronemes (we cannot differentiate between these two scenarios). The complex patterns of 521 dynamic and differential changes suggest a model wherein different FER1 domains modulate 522 each other's function dependent on the context: e.g. the C2D domain binds to other C2 domains 523 within the FER1 proteins and stabilizes a certain protein fold consistent with one of FER1's 524 different functions. There are ample signaling events associated with the micronemes that may 525 act to expose, shield, and/or activate other C2 domains in FER1 [6], such as phosphorylation by 526 CDPK1 [73], PKA [7] or PKG [74, 75], binding of DOC2 upon high $\mathrm{Ca}^{2+}$ [27] and/or lipids 527 becoming available in the signaling pathway due to PAP activity [28] or the guanylate-cyclase528 flippase localized at the apical plasma membrane [63], toward membrane fusion competence. Incapacitating $\mathrm{Ca}^{2+}$-binding in the $\mathrm{C} 2 \mathrm{D}$ domain changes FER1 activity in intracellular

530 parasites which have a low cytoplasmic $\mathrm{Ca}^{2+}$ concentration. This suggests that this domain has a 531 high affinity for $\mathrm{Ca}^{2+}$. Given the absence of critical amino acids able to stabilize $\mathrm{Ca}^{2+}$ in the other $532 \mathrm{C} 2$ domains, it is unlikely that FER1 bind $\mathrm{Ca}^{2+}$ with a low affinity when the signal transduction 533 pathway is engaged. However, in Synaptotagmin-1, a mammalian DOC2 protein, conserved Asp 534 residues in the $\mathrm{C} 2 \mathrm{~A}$ domain interacts with those in $\mathrm{C} 2 \mathrm{~B}$, thereby creating a single $\mathrm{Ca}^{2+}$ pocket in 535 the DOC2 domain [76], which might apply to FER1. Alternatively, high $\mathrm{Ca}^{2+}$ concentration 536 might be transduced by the soluble TgDOC2 protein, which has also been shown to be critical to microneme secretion [27]. In this scenario, paralleled in neurotransmitter release [77], a raise in 
cytoplasmic $\mathrm{Ca}^{2+}$ would drive TgDOC2 to interact with the membrane fusion complex at the primed, radial micronemes as the critical $\mathrm{Ca}^{2+}$-mediated step in membrane fusion and exocytosis. in presence of an intact endogenous allele. The overexpression of the N-terminally tagged wild-

542 type allele resulted somewhat surprisingly in a cytoplasmic localization. Possibly, the N-terminal

543 fusion blocks functionality requiring an accessible FER1 N-terminus, or alternatively, the high

544 level of overexpression saturates the secretory pathway driving the protein into the cytoplasm.

545 Although the second scenario is supported by the higher level of overexpressed protein compared to the $\Delta \mathrm{TM}$ allele, where we do not observe a cytoplasmic signal, access to the Nterminus is likely essential as well. We were unable to obtain stable parasite lines where endogenous FER1 was tagged on either the N- or C-terminus. Neither were we able to generate parasite lines with conditional alleles using any of the systems available in Toxoplasma (tetracycline regulatable promoter replacement or replacing the 3'-UTR with the conditional U1 snRNP motif). Even though a C-terminal tagged PbFLP was stable in P. berghei [47], we conclude that in Toxoplasma tachyzoites the amenability of FER1 to manipulation has an extremely narrow bandwidth. We successfully bypassed this obstacle by generating antisera against FER1 for localization studies, and the overexpression of dominant negative alleles to determine FER1 function.

Another intriguing question generated by our study is the nature of the co-localization of FER1 and VP1 at the apical end. All insights on ferlins in general together with our data suggest that FER1 is microneme associated, which would suggest this signal most likely corresponds with the radial micronemes. Ergo, why is there VP1 in the radial micronemes? VP1 is associated with the acidocalcisomes [78], which it acidifies, as well as with the PLV/VAC [51], where its function is less clear as a distinct v-ATPase acidifies that compartment [20]. This suggests that acidification of the radial micronemes might precede their secretion. Indeed, acidification of the

563 readily releasable vesicle pool is a priming mechanism described in a variety of secretory systems, including neurotransmitter [79] and insulin release [80-82]. In these systems

565 acidification is facilitation by a v-ATPase. Whether VP1 is a functional replacement of this

566 function in $T$. gondii is as yet an untested aspect of this model. Either way, the exact role of the

$567 \mathrm{v}$-ATPase is debated as it has also been shown to act more as a pH sensor [83, 84]. Our

568 observation that VP1 remains apically when all micronemes aggregate upon $\triangle \mathrm{TM}$ 
overexpression could suggest a dynamic composition of this compartment, although we cannot exclude that endogenous FER1 still co-localizes with VP1 under these conditions. This latter scenario fits with our observation that a small pool of micronemes remains sensitive to propranolol induced secretion, which must reside apically to be secreted. reduces MIC2 secretion [29]. But Rab11a's main function is in dense granule secretion with an additional role in cell division [86], which therefore makes its role pleomorphic and complicates to drawing direct connections between Rab11a and FER1 events. Such pluriform role is akin to the defect in microneme apical movement seen upon the knock-out of AP1 [23]. Further strengthening a putative ferlin - Rab11 connection is based on a similar observations for human ferlin Fer1L6, which cycles between the PM and trans-Golgi/recycling endosomes via Rab11 recycling endosomes [41]. Therefore, a connection between $T$. gondii's Rab11a and FER1 at the actual microneme secretion step is quite likely.

Centrin 2 is another player at the apical tip of the parasite with multiple additional localizations in the parasite (centrosome, apical annuli, basal complex) that was recently connected to microneme secretion [26, 87]. Furthermore, a centromeric protein, Chromo1, is also present at the same apical localization, but a putative role with microneme secretion has not been explored [23]. Finally, a conserved phosphoinositide-binding protein, PfPH2, was shown in $P$. falciparum to act on a limited set of microneme proteins, although different populations of micronemes have not been demonstrated in Plasmodium [88]. Moreover, PfH2 localizes close to the apical tip or merozoites, not unlike where FER1 and VP1 co-localize. The paucity in our understanding of microneme secretion is the putative role of SNARE proteins at the site of

592 exocytosis [18]. Although it has been extensively reported that ferlins interface with SNAREs in 593 membrane fusion [44, 71, 72], auditory hair cells might release vesicles mediated by otoferlin 594 without SNAREs [89]. Furthermore, it has been postulated that fast, $\mathrm{Ca}^{2+}$-dependent exocytosis 595 is inconsistent with the role of SNAREs [90] and some exocytosis in absence of SNAREs is possible [91]. Some neurotransmitter is still released when all relevant SNAREs are depleted

597 [91], and indeed, alternative models for SNARE independent neurotransmitter release have been 598 postulated [90]. Indeed, the multiple C2 domains in ferlins have been proposed to be able to support membrane binding integrating the $\mathrm{Ca}^{2+}$-sensing and membrane fusion events [40,92] 
and as such FER1 might act in absence of SNAREs in Toxoplasma. Taken together, a conglomerate of molecular players at the apical end has been identified with roles in microneme exocytosis. Direct links between the observations will be an exciting avenue for future work.

By integrating the new insights generated in this study we propose a model of microneme exocytosis wherein the radial micronemes constitute a readily releasable vesicle pool primed by acidification as shown in Fig 8. Several aspects of this model remain to be tested, and whether it holds up or not, the eclectic collection of molecular players assembling at the site of microneme secretion predict many as yet unanticipated events to be discovered.

\section{Material and Methods}

\section{Parasites and host cells}

Transgenic derivatives of the RH strain were maintained in human foreskin fibroblasts (HFF) or hTERT immortalized HFF cells as previously described [93]. Parasite transfections and selections use $1 \mu \mathrm{M}$ pyrimethamine, $20 \mu \mathrm{M}$ chloramphenicol, $5 \mu \mathrm{g} / \mathrm{ml} \mathrm{FUDR}$, or a combination of $25 \mathrm{mg} / \mathrm{ml}$ mycophenolic acid and $50 \mathrm{mg} / \mathrm{ml}$ xanthine (MPA/X). All parasite lines were cloned by limiting dilution.

\section{Generation of constructs and parasite lines}

All primer sequences are provided in Supplementary Table S1; all plasmids used are provided in Supplementary Table S2. Expression plasmids fusing ddFKBP destabilization domain (DD) with FER1 were generated from tub-DD-Myc-YFP/sagCAT plasmid [55] by replacing YFP with the PCR amplified FER1 CDS (primer pair 1573/1574) by AvrII and XmaI restriction enzymes to generate tub-DD-Myc-FER1 ${ }^{\mathrm{FL}} / \mathrm{sagCAT}$ and in tub DD-YFP-TgNek1-2(MCS)/sagCAT [94]to generate tub-DD-YFP-FER1 ${ }^{\mathrm{FL}} / \mathrm{sagCAT}$. FER1 $\triangle \mathrm{TM}$ constructs were generated by amplifying a 3' section without TM domain (primer pair 1651/1652; deletion of the C-terminal 21 aa) and cloning the product in the FER1-FL plasmids using NheI and XmaI. The FER1 Ca ${ }^{2+}$-binding mutants in the C2D domain were generated by Q5 site directed mutagenesis kit (NEB) using primers 4833/4834 to change positions A1622 and A1634 to C resulting in Asp codon 542 and 545 changes to Ala. 
Plasmid tub-YFP-FER1(TM) encoding only the 31 most C-terminal aa of FER1 including the TM domain was cloned by PCR amplification using primer pair 4786/4788 and cloned by Gibson assembly into BgIII/AvrII digested tub-YFPYFP/sagCAT plasmid [46].

Plasmid tub-IMC3mCherry/DHFR was cloned by swapping IMC3mCherry from tubIMC3mCherry/sagCAT [95] with PmeI/AvrII into tub-YFPYFP(MCS)/DHFR [46].

To generate pmic3-MIC3-Cherry/DHFR $1.3 \mathrm{~kb}$ of promoter region together with $1.2 \mathrm{~kb}$ of the ORF encoding genomic locus was PCR amplified from genomic DNA (primer pair 4864/4865) and Gibson assembled into PmeI and AvrII digested tub-mCherry2/DHFR [96].

\section{Antiserum generation}

641 TgFER1 amino acids 669-877 including the diverse C2 domain DE were PCR amplified using 642 primers Ava-LIC-Fer1-F/R and fused to a 6xHis tag in plasmid pAVA0421 [97], expressed in

643 Escherichia coli BL21, purified by Ni-NTA chromatography (Invitrogen), and used to immunize

644 a guinea pig (Covance, Inc). Serum was affinity purified as described previously [98] against 645 recombinant His6-TgFER1.

\section{Live-cell microscopy}

648 For monitoring egress (P30-YFP and GCaMP3 expression), parasites were grown in hTERT 649 confluent $15 \mathrm{~mm}$ glass bottom cell culture dish (MatTek Corporation, cat \#801002) for $30 \mathrm{hrs}$ 650 and then induced with $2 \mu \mathrm{M}$ Shield-1 for $90 \mathrm{~min}$ at $37^{\circ} \mathrm{C}$. Dishes were live-cell imaged on a 651 Zeiss Axiovert 200M inverted microscope for $15 \mathrm{~min}$ at 2 images per minute. To monitor DD-

652 YFP-FER1 $\triangle T$ TM accumulation a Leica TCS SP5 scanning confocal microscope with incubation 653 chamber in the Boston College Imaging Core in consultation with Bret Judson. Upon addition of $6541 \mu \mathrm{M}$ Shield-1 images were captured every 5 mins for $3 \mathrm{hrs}$. All images were acquired, analyzed 655 and adjusted using Leica, Volocity (Quorum Technologies) and/or ImageJ/FIJI software [99, $656100]$.

\section{8 (Immuno-) fluorescence microscopy}

659 Indirect immunofluorescence assays were performed on intracellular parasites grown for $18 \mathrm{hrs}$ 660 in 6-well plate containing coverslips confluent with HFF cells fixed with 100\% methanol (unless 661 stated otherwise) using primary antisera as listed in Supplementary Table S3. Alexa 488 (A488) 
662 or A594 conjugated goat $\alpha$-mouse, $\alpha$-rabbit, $\alpha$-rat, or $\alpha$-guinea pig were used as secondary

663 antibodies (1:500, Invitrogen). DNA was stained with 4',6-diamidino-2-phenylindole (DAPI).

664 For intracellular IFAs, parasites were allowed to invade and replicate for $24 \mathrm{~h}$ after which $1 \mu \mathrm{M}$

665 Shield-1 was applied for $18 \mathrm{hr}$ (DD-Myc/YFP-FERATM) or $2 \mu \mathrm{M}$ Shield-1 for $3 \mathrm{hr}$ (DD-Myc-

$666 \mathrm{FER}^{\mathrm{FL}}$ ). Extracellular parasites grown \pm Shield-1 for $18 \mathrm{hr}$ were harvested by mechanical lysis

667 and captured on Poly-L-lysine coated coverslips. A Zeiss Axiovert $200 \mathrm{M}$ wide-field

668 fluorescence microscope was used to collect images, which were deconvolved and adjusted for

669 phase contrast using Volocity software). SR- SIM was performed on intracellular parasites fixed 670 with $3.7 \%$ or $4 \%$ PFA in PBS and permeabilized with $0.25 \%$ or $0.5 \%$ TX-100 that were imaged

671 with a Zeiss ELYRA S.1 system in the Boston College Imaging Core in consultation with Bret

672 Judson. All images were acquired, analyzed and adjusted using ZEN software and standard

673 settings. Final image analyses were made with ImageJ/FIJI software [99, 100].

675 Electron microscopy

676 For ultrastructural observations of $T$. gondii-infected cells by thin-section transmission electron

677 microscopy (TEM), infected cells were fixed in $2.5 \%$ glutaraldehyde in $0.1 \mathrm{mM}$ sodium

678 cacodylate (EMS) and processed as described [101]. Ultrathin sections of infected cells were

679 stained before examination with a Philips CM120 EM (Eindhoven, the Netherlands) under 80

$680 \mathrm{kV}$. For immunoelectron microscopy (IEM) samples were prepared as described before [46].

681 Sections were immunolabeled with MIC2 MAb 6D10 in 1\% fish skin gelatin and then with goat 682 anti-IgG antibodies, followed by $10-\mathrm{nm}$ protein A-gold particles before examination with a

683 Philips CM120 electron microscope under $80 \mathrm{kV}$.

\section{Host cell invasion}

686 Extracellular parasites from 80\% naturally lysed flask were induced with $2 \mu \mathrm{M}$ Shield-1 for 90 $687 \mathrm{~min}$ at $37^{\circ} \mathrm{C}$ before they were allowed to invade $\mathrm{HFF}$ host cells for $10 \mathrm{~min}$ at $37^{\circ} \mathrm{C} \mathrm{[7].} \mathrm{The}$ $688 \mathrm{red} /$ green invasion assay was performed as described [102] using Alexa594- and Alexa488689 conjugated SAG1 MAb T41E5. Three images were taken per biological replicate on an EVOS 690 FL (Life Technologies). The number of invaded versus uninvaded parasites were enumerated 691 manually for at least 300 parasites per counted sample. 


\section{Secretagogue induced egress}

694 The egress assay was performed essentially as described previously [46]. Parasites were grown

695 in HFF monolayers for $30 \mathrm{~h}$ after which the phenotype was induced with $1 \mu \mathrm{M}$ Shield-1 for 18

696 hrs. Egress was triggered with 1-3 $\mu \mathrm{M}$ A23187, $500 \mu \mathrm{M}$ propranolol, 50-150 $\mu \mathrm{M}$ BIPPO (kindly

697 shared by Dr. Jeff Dvorin) $0.01-0.1 \%$ saponin or DMSO for $5 \mathrm{~min}$ at $37^{\circ} \mathrm{C}$, followed by IFA

698 with IMC3 and GRA3 antisera. Egressed, permeabilized and intact vacuoles were counted [63].

699100 vacuoles were counted for each experiment and three biological replicates were performed.

\section{Shield-1 induced egress}

702 Parasites were inoculated on HFF coverslips and allowed to grow for $30 \mathrm{hrs}$ and then induced

703 with either $1 \mu \mathrm{M}$ Shield-1 for $2 \mathrm{hrs}$ or $1 \mu \mathrm{M}$ calcium ionophore A23187 for 5 min as a control,

704 prior to fixation with $100 \%$ methanol and IFA staining using MAb 9E10 cMyc and rabbit $\alpha$ MIC8

705 (antisera details in Supplementary Table S1). DNA was stained with 4',6-diamidino-2-

706 phenylindole (DAPI). The number of intact vacuoles per 20 fields was enumerated.

\section{Combined invasion-egress Assay}

709 Parasites were grown for 36 hours, mechanically lysed in standard ED1 parasite medium and

710 allowed to invade coverslips coated in an HFF monolayer for $1 \mathrm{hr}$. All unattached parasites were

711 then washed off with a PBS and coverslips were incubated in $1 \mu \mathrm{M}$ Shield-1 or vehicle control

712 for an additional 2 hrs. Coverslips were then fixed with PFA and IFA was performed as

713 described for a typical red-green invasion assay.

\section{Shield-1 induced microneme secretion}

716 Parasites were grown for $30 \mathrm{hrs}$ in a T25 hTERT containing flask. Flasks were washed once with

717 PBS and once with Endo buffer $\left(20 \mathrm{mM}\right.$ Tris- $\mathrm{H}_{2} \mathrm{SO}_{4} \mathrm{pH} 8.2,44.7 \mathrm{mM} \mathrm{K}_{2} \mathrm{SO}_{4}, 106 \mathrm{mM}$ sucrose,

$7183.5 \mathrm{mg} / \mathrm{ml} \mathrm{BSA}, 10 \mathrm{mM} \mathrm{MgSO}_{4}$ ) [62]. Cells were scraped and parasites mechanically released.

719 Parasites pellets were re-suspended in Endo buffer and treated with either $1 \mu \mathrm{M}$ Shield-1 for 2

720 hrs or A23187 for 5 min prior to processing. All other secretion steps are as previously stated.

721 Supernatants were processed for western blot.

722

723 Microneme secretion by Western blotting 
724 Microneme secretion by western blot was performed as published [103]. Freshly lysed parasites

725 were resuspended in DMEM/FBS and transferred to a 96-well polystyrene round-bottom plate

726 (CELLTREAT Scientific Products). Secretion was induced by 1-3 $\mu \mathrm{M}$ A23187, $500 \mu \mathrm{M}$

727 propranolol, $1 \%$ ethanol or DMSO for 5 min at $37^{\circ} \mathrm{C}$. Constitutive microneme secretion was

728 assessed by incubation without secretagogue at $37^{\circ} \mathrm{C}$ for $60 \mathrm{~min}$. Supernatants were probed by

729 western blot using 6D10 MIC2 MAb and TG17.43 GRA1 MAb and HRP conjugated secondary

730 antiserum. Signals were quantified using a densitometer.

\section{Microneme secretion by IFA}

733 IFA on parasites exposed to a host cell monolayer was performed as reported [46]. Parasites

734 were resuspended in Endo buffer and spun onto HFF cells in a 6-well plate at $28 * \mathrm{~g}, 5 \mathrm{~min}, \mathrm{RT}$

735 and allowed to settle for $20 \mathrm{~min}$ at $37^{\circ} \mathrm{C}$. Secretion was induced by replacing the buffer with $3 \%$

736 FBS in DMEM and $10 \mathrm{mM}$ HEPES (pH 7.2) and incubation at $37^{\circ} \mathrm{C}$ for $5 \mathrm{~min}$. PBS-washed

737 coverslips were fixed with $4 \%$ formaldehyde and $0.02 \%$ glutaraldehyde, and subjected to IFA

738 with anti-Mic3, -Mic5, -Mic8 or Mic10 in the presence of $0.02 \%$ saponin.

\section{Gliding motility trail assay}

741 Trail assays were performed as previously described [22]. Parasites were induced with $1 \mu \mathrm{M}$

742 Shield-1 for $18 \mathrm{hr}$, mechanically released, resuspended in ED1 with $1 \mu \mathrm{M}$ Shield-1 and

743 incubated on poly-L-lysine coated coverslips for $15 \mathrm{~min}$ at $37^{\circ} \mathrm{C}$. Parasites were fixed with $4 \%$

744 formaldehyde and $0.02 \%$ glutaraldehyde and stained with DG52 SAG1 MAb (64) to visualize

745 trails.

746

\section{Statistics.}

748 Student's paired t test and one-way analysis of variance (ANOVA) using post hoc Bonferroni 749 correction were performed.

\section{Acknowledgements}

753 We thank Bret Judson and Dr. Patrick Autissier of the Boston College Imaging and Flow

754 Cytometry Cores, respectively, for infrastructure and support, Dr. Sander Groffen for assistance 
755

with molecular modeling, Emily Stoneburner, Natalie Sandlin, and Elizabeth Gray for technical support, Drs. Gustavo Arrizabalaga, Peter Bradley, Vern Carruthers, Iain Cheeseman, JeanFrançois Dubremetz, Wassim Daher, Jeff Dvorin, Maryse Lebrun, Sebastian Lourido, Sabrina Marion, Silvia Moreno, Naomi Morrissette, Jeroen Saeij, David Sibley, Dominique SoldatiFavre, and Gary Ward for sharing reagents.

This study was supported by National Science Foundation (NSF) Major Research Instrumentation grant 1626072, National Institutes of Health grants AI108251 (B.I.C.), AI060767 (I.C.), AI122042 (M.-J.G), AI099658 (M.-J.G.), and AI122923 (M.-J.G.), and American Cancer Society grant RSG-12-175-01-MPC (M.-J.G.).

\section{Author contributions}

DNAT performed all experiments on the DD-[Myc/YFP]-FER1 $\Delta \mathrm{TM}$ parasites, imaging of the DD-Myc-FER $1^{\mathrm{FL}}$ line, all time lapse and super resolution microscopy and generated and assessed the Asp-Ala mutants, AAD performed all functional studies on the DD-Myc-FER1 ${ }^{\mathrm{FL}}$ parasites, IC performed all electron microscopy studies, BIC cloned FER1 cDNA, established the overexpression plasmids and assessed the initial phenotype, DNAT, AAD and MJG designed the experiments and interpreted the data, MJG wrote the manuscript and all authors reviewed and edited the manuscript.

\section{Conflict of interest}

The authors declare no conflict of interest.

\section{References}

1. Blader, I.J., B.I. Coleman, C.T. Chen, and M.J. Gubbels, 2015. Lytic Cycle of

Toxoplasma gondii: 15 Years Later. Annu Rev Microbiol, 69: 463-85.

2. $\quad$ Carruthers, V.B. and F.M. Tomley, 2008. Microneme proteins in apicomplexans. Subcell Biochem, 47: 33-45.

3. Sheiner, L., J.M. Santos, N. Klages, F. Parussini, N. Jemmely, N. Friedrich, G.E. Ward, and D. Soldati-Favre, 2010. Toxoplasma gondii transmembrane microneme proteins and their modular design. Mol Microbiol.

4. Kafsack, B.F., J.D. Pena, I. Coppens, S. Ravindran, J.C. Boothroyd, and V.B. Carruthers, 2009. Rapid membrane disruption by a perforin-like protein facilitates parasite exit from host cells. Science, 323: 530-3. 
5. Roiko, M.S., N. Svezhova, and V.B. Carruthers, 2014. Acidification Activates Toxoplasma gondii Motility and Egress by Enhancing Protein Secretion and Cytolytic Activity. PLoS Pathog, 10: e1004488.

6. Bullen, H.E., H. Bisio, and D. Soldati-Favre, 2019. The triumvirate of signaling molecules controlling Toxoplasma microneme exocytosis: Cyclic GMP, calcium, and phosphatidic acid. PLoS Pathog, 15: e1007670.

7. Uboldi, A.D., M.L. Wilde, E.A. McRae, R.J. Stewart, L.F. Dagley, L. Yang, N.J. Katris, S.V. Hapuarachchi, M.J. Coffey, A.M. Lehane, C.Y. Botte, R.F. Waller, A.I. Webb, M.J. McConville, and C.J. Tonkin, 2018. Protein kinase A negatively regulates Ca2+

8. Leung, J.M., Y. He, F. Zhang, Y.C. Hwang, E. Nagayasu, J. Liu, J.M. Murray, and K. $\mathrm{Hu}, 2017$. Stability and function of a putative microtubule-organizing center in the human parasite Toxoplasma gondii. Mol Biol Cell, 28: 1361-1378.

9. Kremer, K., D. Kamin, E. Rittweger, J. Wilkes, H. Flammer, S. Mahler, J. Heng, C.J. Tonkin, G. Langsley, S.W. Hell, V.B. Carruthers, D.J. Ferguson, and M. Meissner, 2013. An overexpression screen of Toxoplasma gondii Rab-GTPases reveals distinct transport routes to the micronemes. PLoS Pathog, 9: e1003213.

10. Jacot, D., N. Tosetti, I. Pires, J. Stock, A. Graindorge, Y.F. Hung, H. Han, R. Tewari, I. Kursula, and D. Soldati-Favre, 2016. An Apicomplexan Actin-Binding Protein Serves as a Connector and Lipid Sensor to Coordinate Motility and Invasion. Cell Host Microbe, 20: 731-743.

11. Sakura, T., F. Sindikubwabo, L.K. Oesterlin, H. Bousquet, C. Slomianny, M.A. Hakimi, G. Langsley, and S. Tomavo, 2016. A Critical Role for Toxoplasma gondii Vacuolar Protein Sorting VPS9 in Secretory Organelle Biogenesis and Host Infection. Scientific Reports, 6.

12. Paredes-Santos, T.C., W. de Souza, and M. Attias, 2012. Dynamics and 3D organization of secretory organelles of Toxoplasma gondii. Journal of structural biology, 177: 420-30.

13. Saha, S., B.I. Coleman, R. Dubey, I.J. Blader, and M.J. Gubbels, 2017. Two Phosphoglucomutase Paralogs Facilitate Ionophore-Triggered Secretion of the Toxoplasma Micronemes. mSphere, 2.

14. Venugopal, K. and S. Marion, 2018. Secretory organelle trafficking in Toxoplasma gondii: A long story for a short travel. Int J Med Microbiol, 308: 751-760.

15. Sangare, L.O., T.D. Alayi, B. Westermann, A. Hovasse, F. Sindikubwabo, I. Callebaut, E. Werkmeister, F. Lafont, C. Slomianny, M.A. Hakimi, A. Van Dorsselaer, C. Schaeffer-Reiss, and S. Tomavo, 2016. Unconventional endosome-like compartment and retromer complex in Toxoplasma gondii govern parasite integrity and host infection. Nat Commun, 7: 11191.

16. Tomavo, S., C. Slomianny, M. Meissner, and V.B. Carruthers, 2013. Protein trafficking through the endosomal system prepares intracellular parasites for a home invasion. PLoS Pathog, 9: e1003629.

17. Thornton, L.B., P. Teehan, K. Floyd, C. Cochrane, A. Bergmann, B. Riegel, A.J. Stasic, M. Di Cristina, S.N.J. Moreno, P.D. Roepe, and Z. Dou, 2019. An ortholog of Plasmodium falciparum chloroquine resistance transporter (PfCRT) plays a key role in maintaining the integrity of the endolysosomal system in Toxoplasma gondii to facilitate host invasion. PLoS Pathog, 15: e1007775. 
18. Dubois, D.J. and D. Soldati-Favre, 2019. Biogenesis and secretion of micronemes in Toxoplasma gondii. Cell Microbiol, 21: e13018.

19. McGovern, O.L., Y. Rivera-Cuevas, G. Kannan, A.J. Narwold, and V.B. Carruthers, 2018. Intersection of endocytic and exocytic systems in Toxoplasma gondii. Traffic, 19: 336-353.

20. Stasic, A.J., N.M. Chasen, E.J. Dykes, S.A. Vella, B. Asady, V.J. Starai, and S.N.J. Moreno, 2019. The Toxoplasma Vacuolar H(+)-ATPase Regulates Intracellular $p H$ and Impacts the Maturation of Essential Secretory Proteins. Cell Rep, 27: 2132-2146 e7.

21. Sloves, P.J., S. Delhaye, T. Mouveaux, E. Werkmeister, C. Slomianny, A. Hovasse, T. Dilezitoko Alayi, I. Callebaut, R.Y. Gaji, C. Schaeffer-Reiss, A. Van Dorsselear, V.B. Carruthers, and S. Tomavo, 2012. Toxoplasma sortilin-like receptor regulates protein transport and is essential for apical secretory organelle biogenesis and host infection. Cell Host Microbe, 11: 515-27.

22. Morlon-Guyot, J., S. Pastore, L. Berry, M. Lebrun, and W. Daher, 2015. Toxoplasma gondii Vps11, a subunit of HOPS and CORVET tethering complexes, is essential for the biogenesis of secretory organelles. Cellular Microbiology.

23. Venugopal, K., E. Werkmeister, N. Barois, J.M. Saliou, A. Poncet, L. Huot, F. Sindikubwabo, M.A. Hakimi, G. Langsley, F. Lafont, and S. Marion, 2017. Dual role of the Toxoplasma gondii clathrin adaptor AP1 in the sorting of rhoptry and microneme proteins and in parasite division. PLoS Pathog, 13: e1006331.

24. Bradley, P.J. and J.C. Boothroyd, 2001. The pro region of Toxoplasma ROP1 is a rhoptry-targeting signal. Int J Parasitol, 31: 1177-86.

25. Bradley, P.J., N. Li, and J.C. Boothroyd, 2004. A GFP-based motif-trap reveals a novel mechanism of targeting for the Toxoplasma ROP4 protein. Mol Biochem Parasitol, 137: 111-20.

26. Lentini, G., D.J. Dubois, B. Maco, D. Soldati-Favre, and K. Frenal, 2019. The roles of Centrin 2 and Dynein Light Chain 8 a in apical secretory organelles discharge of Toxoplasma gondii. Traffic.

27. Farrell, A., S. Thirugnanam, A. Lorestani, J.D. Dvorin, K.P. Eidell, D.J. Ferguson, B.R. Anderson-White, M.T. Duraisingh, G.T. Marth, and M.J. Gubbels, 2012. A DOC2 protein identified by mutational profiling is essential for apicomplexan parasite exocytosis. Science, 335: 218-21.

28. Bullen, H.E., Y. Jia, Y. Yamaryo-Botte, H. Bisio, O. Zhang, N.K. Jemelin, J.B. Marq, V. Carruthers, C.Y. Botte, and D. Soldati-Favre, 2016. Phosphatidic Acid-Mediated Signaling Regulates Microneme Secretion in Toxoplasma. Cell Host Microbe, 19: 34960.

29. Venugopal, K., S. Chehade, E. Werkmeister, N. Barois, J. Periz, F. Lafont, I. Tardieux, J. Khalife, G. Langsley, M. Meissner, and S. Marion, 2019. Rab11A regulates the constitutive secretory pathway during Toxoplasma gondii invasion of host cells and parasite replication. bioRxiv.

30. Bullen, H.E. and D. Soldati-Favre, 2016. A central role for phosphatidic acid as a lipid mediator of regulated exocytosis in apicomplexa. FEBS Lett, 590: 2469-81.

31. Gras, S., E. Jimenez-Ruiz, C.M. Klinger, K. Schneider, A. Kling1, L. Lemgruber, and M. Meissner, 2019. An endocytic-secretory cycle participates in Toxoplasma gondii in motility. PLoS Biol, 17: e3000060. 
32. Periz, J., M. Del Rosario, A. McStea, S. Gras, C. Loney, L. Wang, M.L. MartinFernandez, and M. Meissner, 2019. A highly dynamic F-actin network regulates transport and recycling of micronemes in Toxoplasma gondii vacuoles. Nat Commun, 10: 4183.

33. Martens, S. and H.T. McMahon, 2008. Mechanisms of membrane fusion: disparate players and common principles. Nat Rev Mol Cell Biol, 9: 543-56.

34. Martens, S., 2010. Role of C2 domain proteins during synaptic vesicle exocytosis. Biochem Soc Trans, 38: 213-6.

35. Corbalan-Garcia, S. and J.C. Gomez-Fernandez, 2014. Signaling through C2 domains: more than one lipid target. Biochim Biophys Acta, 1838: 1536-47.

36. Striegel, A.R., L.M. Biela, C.S. Evans, Z. Wang, J.B. Delehoy, R.B. Sutton, E.R. Chapman, and N.E. Reist, 2012. Calcium binding by synaptotagmin's C2A domain is an essential element of the electrostatic switch that triggers synchronous synaptic transmission. J Neurosci, 32: 1253-60.

37. Davis, D.B., K.R. Doherty, A.J. Delmonte, and E.M. McNally, 2002. Calcium-sensitive phospholipid binding properties of normal and mutant ferlin C2 domains. J Biol Chem, 277: 22883-8.

38. Verdaguer, N., S. Corbalan-Garcia, W.F. Ochoa, I. Fita, and J.C. Gomez-Fernandez, 1999. $\mathrm{Ca}(2+)$ bridges the $C 2$ membrane-binding domain of protein kinase Calpha directly to phosphatidylserine. EMBO J, 18: 6329-38.

39. Chapman, E.R. and A.F. Davis, 1998. Direct interaction of a Ca2+-binding loop of synaptotagmin with lipid bilayers. J Biol Chem, 273: 13995-4001.

40. Lek, A., F.J. Evesson, R.B. Sutton, K.N. North, and S.T. Cooper, 2012. Ferlins: regulators of vesicle fusion for auditory neurotransmission, receptor trafficking and membrane repair. Traffic, 13: 185-94.

41. Redpath, G.M., R.A. Sophocleous, L. Turnbull, C.B. Whitchurch, and S.T. Cooper, 2016. Ferlins Show Tissue-Specific Expression and Segregate as Plasma Membrane/Late Endosomal or Trans-Golgi/Recycling Ferlins. Traffic, 17: 245-66.

42. Roux, I., S. Safieddine, R. Nouvian, M. Grati, M.C. Simmler, A. Bahloul, I. Perfettini, M. Le Gall, P. Rostaing, G. Hamard, A. Triller, P. Avan, T. Moser, and C. Petit, 2006. Otoferlin, defective in a human deafness form, is essential for exocytosis at the auditory ribbon synapse. Cell, 127: 277-89.

43. Pangrsic, T., E. Reisinger, and T. Moser, 2012. Otoferlin: a multi-C2 domain protein essential for hearing. Trends in neurosciences, 35: 671-80.

44. Hams, N., M. Padmanarayana, W. Qiu, and C.P. Johnson, 2017. Otoferlin is a multivalent calcium-sensitive scaffold linking SNAREs and calcium channels. Proc Natl Acad Sci U S A, 114: 8023-8028.

45. Michalski, N., J.D. Goutman, S.M. Auclair, J. Boutet de Monvel, M. Tertrais, A. Emptoz, A. Parrin, S. Nouaille, M. Guillon, M. Sachse, D. Ciric, A. Bahloul, J.P. Hardelin, R.B. Sutton, P. Avan, S.S. Krishnakumar, J.E. Rothman, D. Dulon, S. Safieddine, and C. Petit, 2017. Otoferlin acts as a Ca(2+) sensor for vesicle fusion and vesicle pool replenishment at auditory hair cell ribbon synapses. Elife, 6.

46. Coleman, B.I., S. Saha, S. Sato, K. Engelberg, D.J.P. Ferguson, I. Coppens, M. Lodoen, and M.-J. Gubbels, 2018. A member of the ferlin calcium sensor family is essential for Toxoplasma gondii rhoptry secretion. mBio, 9: e01510-18. 
47. Obrova, K., M. Cyrklaff, R. Frank, G.R. Mair, and A.K. Mueller, 2018. Transmission of the malaria parasite requires ferlin for gamete egress from the red blood cell. Cell Microbiol: e12999.

48. Sidik, S.M., D. Huet, S.M. Ganesan, M.H. Huynh, T. Wang, A.S. Nasamu, P. Thiru, J.P. Saeij, V.B. Carruthers, J.C. Niles, and S. Lourido, 2016. A Genome-wide CRISPR Screen in Toxoplasma Identifies Essential Apicomplexan Genes. Cell, 166: 1423-1435 e12.

49. Padgett, L.R., G. Arrizabalaga, and W.J. Sullivan, Jr., 2017. Targeting of tail-anchored membrane proteins to subcellular organelles in Toxoplasma gondii. Traffic, 18: 149158.

50. Breinich, M.S., D.J. Ferguson, B.J. Foth, G.G. van Dooren, M. Lebrun, D.V. Quon, B. Striepen, P.J. Bradley, F. Frischknecht, V.B. Carruthers, and M. Meissner, 2009. A Dynamin Is Required for the Biogenesis of Secretory Organelles in Toxoplasma gondii. Curr Biol, 19: 277-86.

51. Miranda, K., D.A. Pace, R. Cintron, J.C. Rodrigues, J. Fang, A. Smith, P. Rohloff, E. Coelho, F. de Haas, W. de Souza, I. Coppens, L.D. Sibley, and S.N. Moreno, 2010. Characterization of a novel organelle in Toxoplasma gondii with similar composition and function to the plant vacuole. Mol Microbiol, 76: 1358-75.

52. Drozdowicz, Y.M., M. Shaw, M. Nishi, B. Striepen, H.A. Liwinski, D.S. Roos, and P.A. Rea, 2003. Isolation and characterization of TgVP1, a type I vacuolar H+-translocating pyrophosphatase from Toxoplasma gondii. The dynamics of its subcellular localization and the cellular effects of a diphosphonate inhibitor. J Biol Chem, 278: 1075-85.

53. Luo, S., F.A. Ruiz, and S.N. Moreno, 2005. The acidocalcisome Ca2+-ATPase (TgA1) of Toxoplasma gondii is required for polyphosphate storage, intracellular calcium homeostasis and virulence. Mol Microbiol, 55: 1034-45.

54. Francia, M.E., S. Wicher, D.A. Pace, J. Sullivan, S.N. Moreno, and G. Arrizabalaga, 2011. A Toxoplasma gondii protein with homology to intracellular type $\mathrm{Na}(+) / \mathrm{H}(+)$ exchangers is important for osmoregulation and invasion. Exp Cell Res.

55. Herm-Gotz, A., C. Agop-Nersesian, S. Munter, J.S. Grimley, T.J. Wandless, F. Frischknecht, and M. Meissner, 2007. Rapid control of protein level in the apicomplexan Toxoplasma gondii. Nat Methods, 4: 1003-5.

56. Garrison, E., M. Treeck, E. Ehret, H. Butz, T. Garbuz, B.P. Oswald, M. Settles, J. Boothroyd, and G. Arrizabalaga, 2012. A forward genetic screen reveals that calciumdependent protein kinase 3 regulates egress in Toxoplasma. PLoS Pathog, 8: e1003049.

57. Lourido, S., K. Tang, and L.D. Sibley, 2012. Distinct signalling pathways control Toxoplasma egress and host-cell invasion. Embo J, 31: 4524-34.

58. McCoy, J.M., L. Whitehead, G.G. van Dooren, and C.J. Tonkin, 2012. TgCDPK3 Regulates Calcium-Dependent Egress of Toxoplasma gondii from Host Cells. PLoS Pathog, 8: e1003066.

59. Parussini, F., I. Coppens, P.P. Shah, S.L. Diamond, and V.B. Carruthers, 2010. Cathepsin L occupies a vacuolar compartment and is a protein maturase within the endo/exocytic system of Toxoplasma gondii. Mol Microbiol, 76: 1340-57.

60. Brydges, S.D., J.M. Harper, F. Parussini, I. Coppens, and V.B. Carruthers, 2008. A transient forward-targeting element for microneme-regulated secretion in Toxoplasma gondii. Biology of the Cell, 100: 253-264.

61. Nishi, M., K. Hu, J.M. Murray, and D.S. Roos, 2008. Organellar dynamics during the cell cycle of Toxoplasma gondii. J Cell Sci, 121: 1559-1568. 
971

972

973

974

975

976

977

978

979

980

981

982

983

984

985

986

987

988

989

990

991

992

993

994

995

996

997

998

999

1000

1001

1002

1003

1004

1005

1006

1007

1008

1009

1010

1011

1012

1013

1014

62. Endo, T. and K. Yagita, 1990. Effect of extracellular ions on motility and cell entry in Toxoplasma gondii. J Protozool, 37: 133-8.

63. Bisio, H., M. Lunghi, M. Brochet, and D. Soldati-Favre, 2019. Phosphatidic acid governs natural egress in Toxoplasma gondii via a guanylate cyclase receptor platform. Nat Microbiol, 4: 420-428.

64. Kafsack, B.F., C. Beckers, and V.B. Carruthers, 2004. Synchronous invasion of host cells by Toxoplasma gondii. Mol Biochem Parasitol, 136: 309-11.

65. Vog1, C., I. Panou, G. Yamanbaeva, C. Wichmann, S.J. Mangosing, F. Vilardi, A.A. Indzhykulian, T. Pangrsic, R. Santarelli, M. Rodriguez-Ballesteros, T. Weber, S. Jung, E. Cardenas, X. Wu, S.M. Wojcik, K.Y. Kwan, I. Del Castillo, B. Schwappach, N. Strenzke, D.P. Corey, S.Y. Lin, and T. Moser, 2016. Tryptophan-rich basic protein (WRB) mediates insertion of the tail-anchored protein otoferlin and is required for hair cell exocytosis and hearing. EMBO J, 35: 2536-2552.

66. Kaeser, P.S. and W.G. Regehr, 2014. Molecular mechanisms for synchronous, asynchronous, and spontaneous neurotransmitter release. Annu Rev Physiol, 76: 33363.

67. Kaeser, P.S. and W.G. Regehr, 2017. The readily releasable pool of synaptic vesicles. Curr Opin Neurobiol, 43: 63-70.

68. Meese, S., A.P. Cepeda, F. Gahlen, C.M. Adams, R. Ficner, A.J. Ricci, S. Heller, E. Reisinger, and M. Herget, 2017. Activity-Dependent Phosphorylation by CaMKIIdelta Alters the $\mathrm{Ca}(2+)$ Affinity of the Multi-C2-Domain Protein Otoferlin. Front Synaptic Neurosci, 9: 13.

69. Pangrsic, T., L. Lasarow, K. Reuter, H. Takago, M. Schwander, D. Riedel, T. Frank, L.M. Tarantino, J.S. Bailey, N. Strenzke, N. Brose, U. Muller, E. Reisinger, and T. Moser, 2010. Hearing requires otoferlin-dependent efficient replenishment of synaptic vesicles in hair cells. Nat Neurosci, 13: 869-76.

70. Heidrych, P., U. Zimmermann, S. Kuhn, C. Franz, J. Engel, S.V. Duncker, B. Hirt, C.M. Pusch, P. Ruth, M. Pfister, W. Marcotti, N. Blin, and M. Knipper, 2009. Otoferlin interacts with myosin VI: implications for maintenance of the basolateral synaptic structure of the inner hair cell. Hum Mol Genet, 18: 2779-90.

71. Ramakrishnan, N.A., M.J. Drescher, B.J. Morley, P.M. Kelley, and D.G. Drescher, 2014. Calcium regulates molecular interactions of otoferlin with soluble NSF attachment protein receptor (SNARE) proteins required for hair cell exocytosis. J Biol Chem, 289: 8750-66.

72. Johnson, C.P. and E.R. Chapman, 2010. Otoferlin is a calcium sensor that directly regulates SNARE-mediated membrane fusion. J Cell Biol, 191: 187-97.

73. Lourido, S., J. Shuman, C. Zhang, K.M. Shokat, R. Hui, and L.D. Sibley, 2010. Calciumdependent protein kinase 1 is an essential regulator of exocytosis in Toxoplasma. Nature, 465: 359-62.

74. Donald, R.G. and P.A. Liberator, 2002. Molecular characterization of a coccidian parasite cGMP dependent protein kinase. Mol Biochem Parasitol, 120: 165-75.

75. Jia, Y., J.B. Marq, H. Bisio, D. Jacot, C. Mueller, L. Yu, J. Choudhary, M. Brochet, and D. Soldati-Favre, 2017. Crosstalk between PKA and PKG controls pH-dependent host cell egress of Toxoplasma gondii. EMBO J. 
76. Evans, C.S., Z. He, H. Bai, X. Lou, P. Jeggle, R.B. Sutton, J.M. Edwardson, and E.R. Chapman, 2016. Functional analysis of the interface between the tandem C2 domains of synaptotagmin-1. Mol Biol Cell, 27: 979-89.

77. Shin, O.H., 2014. Exocytosis and synaptic vesicle fusion. Comprehensive Physiology, 4 : 149-175.

78. Luo, S., M. Vieira, J. Graves, L. Zhong, and S.N. Moreno, 2001. A plasma membranetype Ca(2+)-ATPase co-localizes with a vacuolar $H(+)$-pyrophosphatase to acidocalcisomes of Toxoplasma gondii. EMBO J, 20: 55-64.

79. Morel, N. and S. Poea-Guyon, 2015. The membrane domain of vacuolar H(+)ATPase: $a$ crucial player in neurotransmitter exocytotic release. Cell Mol Life Sci, 72: 2561-73.

80. Morel, N., J.C. Dedieu, and J.M. Philippe, 2003. Specific sorting of the al isoform of the $V$-H+ATPase a subunit to nerve terminals where it associates with both synaptic vesicles and the presynaptic plasma membrane. J Cell Sci, 116: 4751-62.

81. Rorsman, P. and E. Renstrom, 2003. Insulin granule dynamics in pancreatic beta cells. Diabetologia, 46: 1029-45.

82. Barg, S., P. Huang, L. Eliasson, D.J. Nelson, S. Obermuller, P. Rorsman, F. Thevenod, and E. Renstrom, 2001. Priming of insulin granules for exocytosis by granular Cl(-) uptake and acidification. J Cell Sci, 114: 2145-54.

83. Poea-Guyon, S., M.R. Ammar, M. Erard, M. Amar, A.W. Moreau, P. Fossier, V. Gleize, N. Vitale, and N. Morel, 2013. The V-ATPase membrane domain is a sensor of granular pH that controls the exocytotic machinery. J Cell Biol, 203: 283-98.

84. Wang, D. and P.R. Hiesinger, 2013. The vesicular ATPase: a missing link between acidification and exocytosis. J Cell Biol, 203: 171-3.

85. Andenmatten, N., S. Egarter, A.J. Jackson, N. Jullien, J.P. Herman, and M. Meissner, 2012. Conditional genome engineering in Toxoplasma gondii uncovers alternative invasion mechanisms. Nat Methods, 10: 125-7.

86. Agop-Nersesian, C., B. Naissant, F. Ben Rached, M. Rauch, A. Kretzschmar, S. Thiberge, R. Menard, D.J. Ferguson, M. Meissner, and G. Langsley, 2009. Rab11Acontrolled assembly of the inner membrane complex is required for completion of apicomplexan cytokinesis. PLoS Pathog, 5: e1000270.

87. Leung, J.M., J. Liu, L.A. Wetzel, and K. Hu, 2019. Centrin2 from the human parasite Toxoplasma gondii is required for its invasion and intracellular replication. J Cell Sci, 132.

88. Ebrahimzadeh, Z., A. Mukherjee, M.E. Crochetiere, A. Sergerie, S. Amiar, L.A. Thompson, D. Gagnon, D. Gaumond, R.V. Stahelin, J.B. Dacks, and D. Richard, 2019. A pan-apicomplexan phosphoinositide-binding protein acts in malarial microneme exocytosis. EMBO Rep, 20.

89. Nouvian, R., J. Neef, A.V. Bulankina, E. Reisinger, T. Pangrsic, T. Frank, S. Sikorra, N. Brose, T. Binz, and T. Moser, 2011. Exocytosis at the hair cell ribbon synapse apparently operates without neuronal SNARE proteins. Nat Neurosci, 14: 411-3.

90. Meriney, S.D., J.A. Umbach, and C.B. Gundersen, 2014. Fast, Ca2+-dependent exocytosis at nerve terminals: shortcomings of SNARE-based models. Prog Neurobiol, 121: 55-90.

91. Liu, Y., Y. Sugiura, T.C. Sudhof, and W. Lin, 2019. Ablation of All Synaptobrevin vSNAREs Blocks Evoked But Not Spontaneous Neurotransmitter Release at Neuromuscular Synapses. J Neurosci, 39: 6049-6066. 
1061

1062

1063

1064

1065

1066

1067

1068

1069

1070

1071

1072

1073

1074

1075

1076

1077

1078

1079

1080

1081

1082

1083

1084

1085

1086

1087

1088

1089

1090

1091

1092

1093

1094

1095

1096

1097

1098

1099

1100

1101

1102

1103

1104

1105

1106

92. Lek, A., M. Lek, K.N. North, and S.T. Cooper, 2010. Phylogenetic analysis of ferlin genes reveals ancient eukaryotic origins. BMC Evol Biol, 10: 231.

93. Roos, D.S., R.G. Donald, N.S. Morrissette, and A.L. Moulton, 1994. Molecular tools for genetic dissection of the protozoan parasite Toxoplasma gondii. Methods Cell Biol, 45: 27-63.

94. Chen, C.T. and M.J. Gubbels, 2013. The Toxoplasma gondii centrosome is the platform for internal daughter budding as revealed by a Nek1 kinase mutant. J Cell Sci, 126: 3344-55.

95. Anderson-White, B.R., F.D. Ivey, K. Cheng, T. Szatanek, A. Lorestani, C.J. Beckers, D.J. Ferguson, N. Sahoo, and M.J. Gubbels, 2011. A family of intermediate filament-like proteins is sequentially assembled into the cytoskeleton of Toxoplasma gondii. Cell Microbiol, 13: 18-31.

96. Schaeffer, M., S.J. Han, T. Chtanova, G.G. van Dooren, P. Herzmark, Y. Chen, B. Roysam, B. Striepen, and E.A. Robey, 2009. Dynamic imaging of T cell-parasite interactions in the brains of mice chronically infected with Toxoplasma gondii. J Immunol, 182: 6379-93.

97. Alexandrov, A., M. Vignali, D.J. LaCount, E. Quartley, C. de Vries, D. De Rosa, J. Babulski, S.F. Mitchell, L.W. Schoenfeld, S. Fields, W.G. Hol, M.E. Dumont, E.M. Phizicky, and E.J. Grayhack, 2004. A facile method for high-throughput co-expression of protein pairs. Mol Cell Proteomics, 3: 934-8.

98. Gubbels, M.J., S. Vaishnava, N. Boot, J.F. Dubremetz, and B. Striepen, 2006. A MORNrepeat protein is a dynamic component of the Toxoplasma gondii cell division apparatus. J Cell Sci, 119: 2236-45.

99. Abramoff, M.D., P.J. Magalhaes, and S.J. Ram, 2004. Image Processing with ImageJ. Biophotonics International, 11:36-42.

100. Schindelin, J., I. Arganda-Carreras, E. Frise, V. Kaynig, M. Longair, T. Pietzsch, S. Preibisch, C. Rueden, S. Saalfeld, B. Schmid, J.Y. Tinevez, D.J. White, V. Hartenstein, K. Eliceiri, P. Tomancak, and A. Cardona, 2012. Fiji: an open-source platform for biological-image analysis. Nat Methods, 9: 676-82.

101. Coppens, I. and K.A. Joiner, 2003. Host but not parasite cholesterol controls Toxoplasma cell entry by modulating organelle discharge. Mol Biol Cell, 14: 3804-20.

102. Carey, K.L., N.J. Westwood, T.J. Mitchison, and G.E. Ward, 2004. A small-molecule approach to studying invasive mechanisms of Toxoplasma gondii. Proc Natl Acad Sci U S A, 101: 7433-8.

103. Carruthers, V.B. and L.D. Sibley, 1999. Mobilization of intracellular calcium stimulates microneme discharge in Toxoplasma gondii. Mol Microbiol, 31: 421-8.

104. Jimenez, J.L. and R. Bashir, 2007. In silico functional and structural characterisation of ferlin proteins by mapping disease-causing mutations and evolutionary information onto three-dimensional models of their C2 domains. J Neurol Sci, 260: 114-23.

105. Hartmann, J., K. Hu, C.Y. He, L. Pelletier, D.S. Roos, and G. Warren, 2006. Golgi and centrosome cycles in Toxoplasma gondii. Mol Biochem Parasitol, 145: 125-7.

106. Wan, K.L., V.B. Carruthers, L.D. Sibley, and J.W. Ajioka, 1997. Molecular characterisation of an expressed sequence tag locus of Toxoplasma gondii encoding the micronemal protein MIC2. Mol Biochem Parasitol, 84: 203-14.

107. Garcia-Reguet, N., M. Lebrun, M.N. Fourmaux, O. Mercereau-Puijalon, T. Mann, C.J. Beckers, B. Samyn, J. Van Beeumen, D. Bout, and J.F. Dubremetz, 2000. The microneme 
protein MIC3 of Toxoplasma gondii is a secretory adhesin that binds to both the surface of the host cells and the surface of the parasite. Cell Microbiol, 2: 353-64.

108. Brydges, S.D., X.W. Zhou, M.H. Huynh, J.M. Harper, J. Mital, K.D. Adjogble, W. Daubener, G.E. Ward, and V.B. Carruthers, 2006. Targeted deletion of MIC5 enhances trimming proteolysis of Toxoplasma invasion proteins. Eukaryot Cell, 5: 2174-83.

109. Meissner, M., M. Reiss, N. Viebig, V.B. Carruthers, C. Toursel, S. Tomavo, J.W. Ajioka, and D. Soldati, 2002. A family of transmembrane microneme proteins of Toxoplasma gondii contain EGF-like domains and function as escorters. J Cell Sci, 115: 563-74.

110. Hoff, E.F., S.H. Cook, G.D. Sherman, J.M. Harper, D.J. Ferguson, J.F. Dubremetz, and V.B. Carruthers, 2001. Toxoplasma gondii: molecular cloning and characterization of a novel 18-kDa secretory antigen, TgMIC10. Exp Parasitol, 97: 77-88.

111. Harper, J.M., M.H. Huynh, I. Coppens, F. Parussini, S. Moreno, and V.B. Carruthers, 2006. A cleavable propeptide influences Toxoplasma infection by facilitating the trafficking and secretion of the TgMIC2-M2AP invasion complex. Molecular Biology of the Cell, 17: 4551-4563.

112. Carey, K.L., A.M. Jongco, K. Kim, and G.E. Ward, 2004. The Toxoplasma gondii rhoptry protein ROP4 is secreted into the parasitophorous vacuole and becomes phosphorylated in infected cells. Eukaryot Cell, 3: 1320-30.

113. Cesbron-Delauw, M.F., B. Guy, G. Torpier, R.J. Pierce, G. Lenzen, J.Y. Cesbron, H. Charif, P. Lepage, F. Darcy, and J.P. Lecocq, 1989. Molecular characterization of a 23kilodalton major antigen secreted by Toxoplasma gondii. Proc Natl Acad Sci U S A, 86: 7537-41.

114. Burg, J.L., D. Perelman, L.H. Kasper, P.L. Ware, and J.C. Boothroyd, 1988. Molecular analysis of the gene encoding the major surface antigen of Toxoplasma gondii. Journal of immunology, 141: 3584-91.

115. Dubremetz, J.F., A. Achbarou, D. Bermudes, and K.A. Joiner, 1993. Kinetics and pattern of organelle exocytosis during Toxoplasma gondii/host-cell interaction. Parasitol Res, 79: $402-8$.

116. Couvreur, G., A. Sadak, B. Fortier, and J.F. Dubremetz, 1988. Surface antigens of Toxoplasma gondii. Parasitology, 97 ( Pt 1): 1-10.

117. Sadak, A., Z. Taghy, B. Fortier, and J.F. Dubremetz, 1988. Characterization of a Family of Rhoptry Proteins of Toxoplasma-Gondii. Molecular and Biochemical Parasitology, 29: 203-211.

118. Morrissette, N.S. and L.D. Sibley, 2002. Disruption of microtubules uncouples budding and nuclear division in Toxoplasma gondii. J Cell Sci, 115: 1017-25.

119. Jerka-Dziadosz, M., L.M. Jenkins, E.M. Nelsen, N.E. Williams, R. Jaeckel-Williams, and J. Frankel, 1995. Cellular polarity in ciliates: persistence of global polarity in a disorganized mutant of Tetrahymena thermophila that disrupts cytoskeletal organization. Dev Biol, 169: 644-61. 


\section{$1147 \quad$ Figure 1}
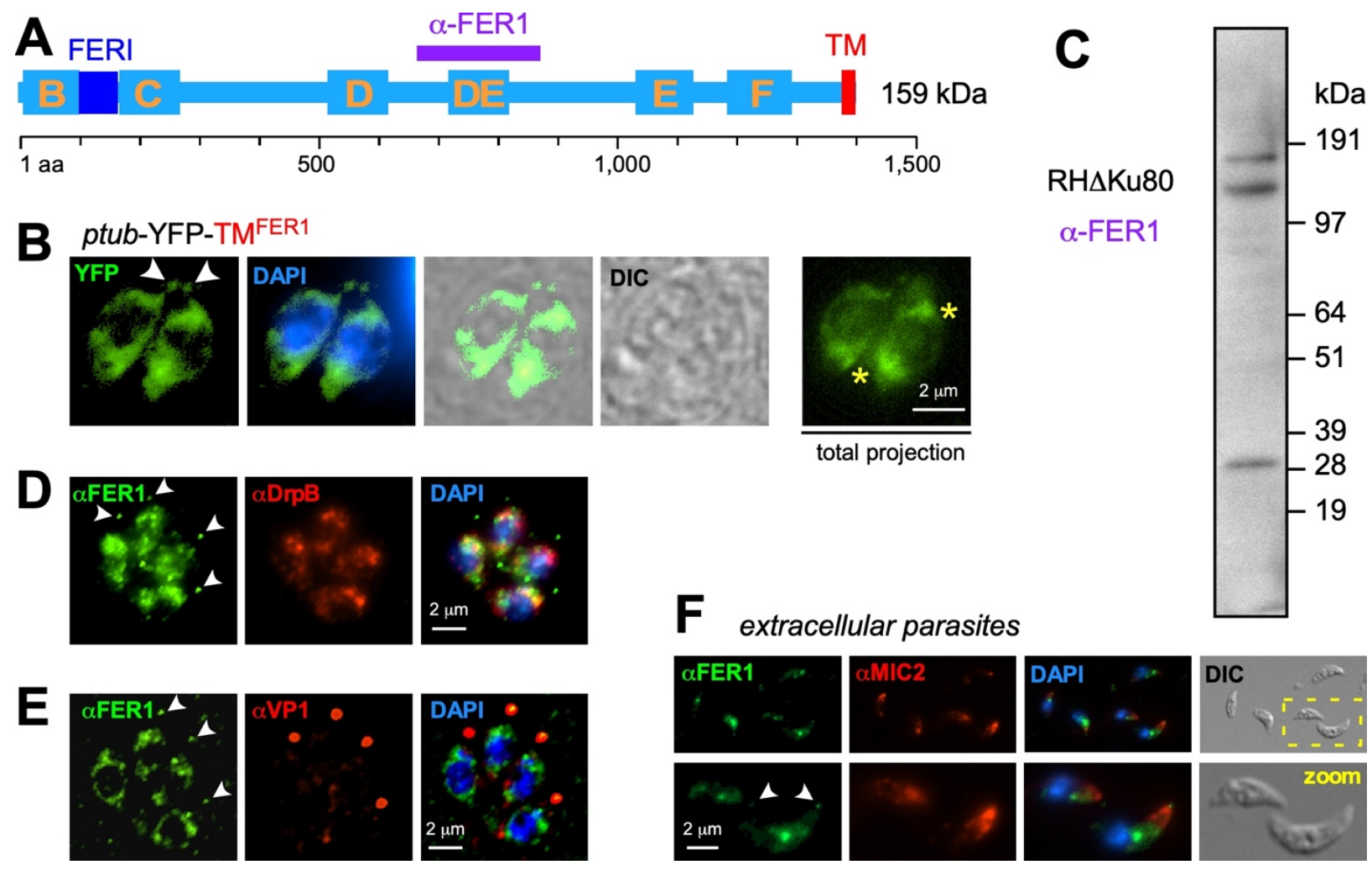

Figure 1. FER1 localizes to the secretory pathway and the conoid region. A. Schematic

1150 representation of TgFER1. Yellow letters mark the C2 domains; the aa 669-877 region used to

1151 generate a specific antiserum is marked in purple; FERI is a domain conserved in most ferlins

1152 with unknown function; TM is the transmembrane domain. B. Overexpression of a YFP fusion to

1153 the FER1 TM domain (C-terminal 31 aa, comprising 10 aa before the 21 extremely C-terminal

1154 TM domain) only under the tubulin promoter (ptub). Arrowheads mark YFP localization to the

1155 conoid region; yellow asterisk mark the perinuclear region reminiscent of the ER. Left panels

1156 represent a single z-layer from deconvolved images collected by wide-field microscopy; in the

1157 right panel all z-stacks are projected. C. Western blot analysis with the affinity purified guinea

1158 pig polyclonal antiserum generated against the FER1 region marked in panel A. Total lysate of

1159 wild type (RH $\Delta \mathrm{Ku} 80)$ parasites was loaded. D-F. Analysis of the affinity purified FER1

1160 antiserum by IFA co-stained with $\alpha$-DrpB serum marking the ELC (D) and $\alpha$-VP1 serum

1161 marking the plant like vacuole (E). Arrowheads mark FER1 localization to the conoid region,

1162 which colocalizes with VP1. The area corresponding with the yellow box in the top right panel

1163 of $\mathrm{F}$ is magnified in the lower panels (zoom). Parasites in A and F were fixed with 4\% PFA,

1164 parasites in D and E with 100\% methanol. 


\section{Figure 2}

1166

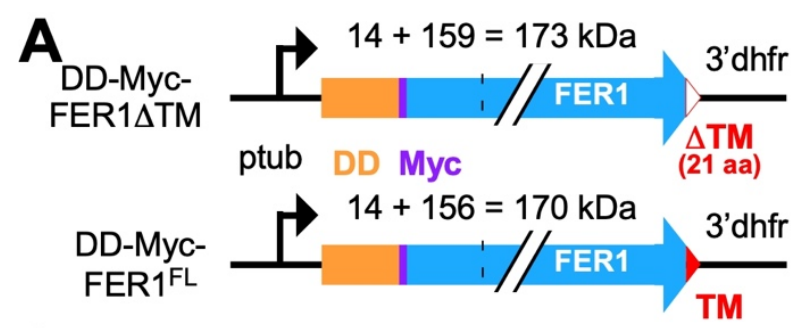

C $\mathrm{RH}$ $\Delta \mathrm{Ku} 80$
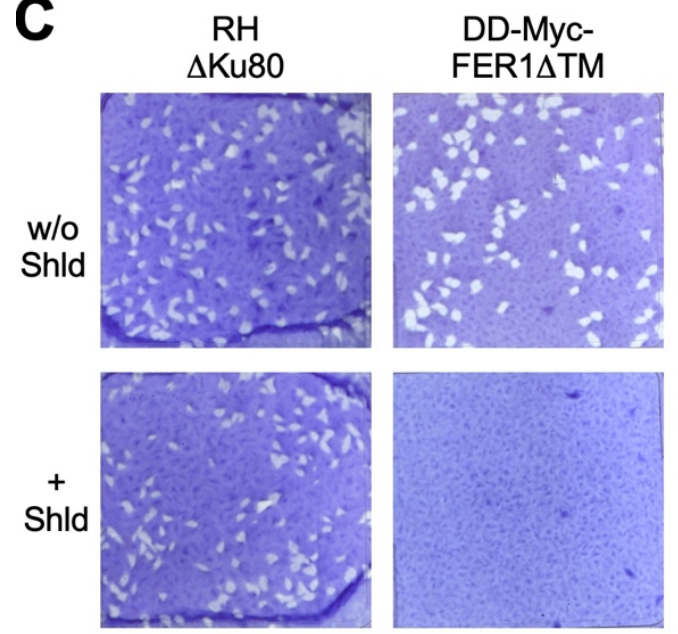
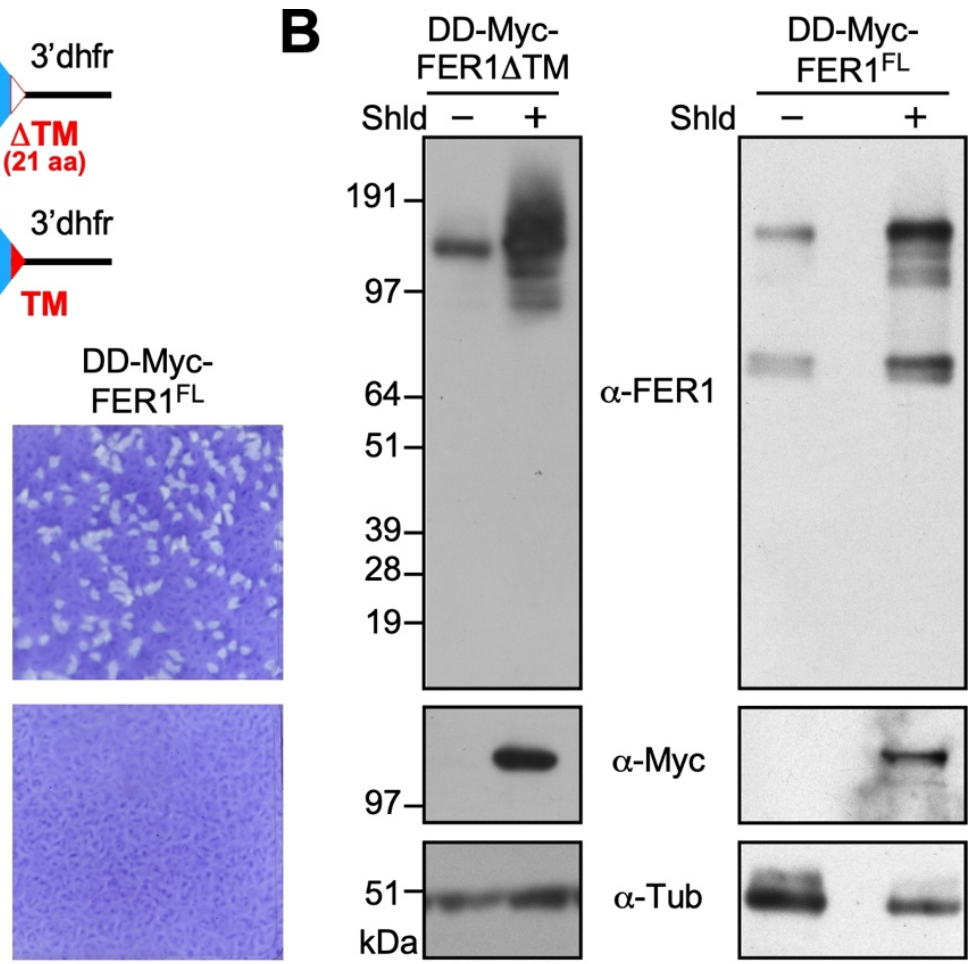

1169 Figure 2. Generation and validation of conditional FER1 overexpression parasite lines. A.

1170 Schematic representation of the overexpression constructs driven by the strong constitutive $\alpha$ -

1171 tubulin promoter (ptub). DD: destabilization domain; Myc: cMyc epitope tag; TM:

1172 transmembrane domain; FL: full length. B. Western blot analysis of the overexpression parasite

1173 lines. Polyclonal guinea pig FER1 antiserum as in Fig 1. Monoclonal antibody12G10

1174 recognizing $\alpha$-tubulin was used as loading control. Parasites were induced with $1 \mu \mathrm{M}$ Shield-1

1175 for $24 \mathrm{hrs}$. C. plaque assays of infected HFF monolayers grown for 7 days $\pm 1 \mu \mathrm{M}$ Shield-1. 


\section{Figure 3}
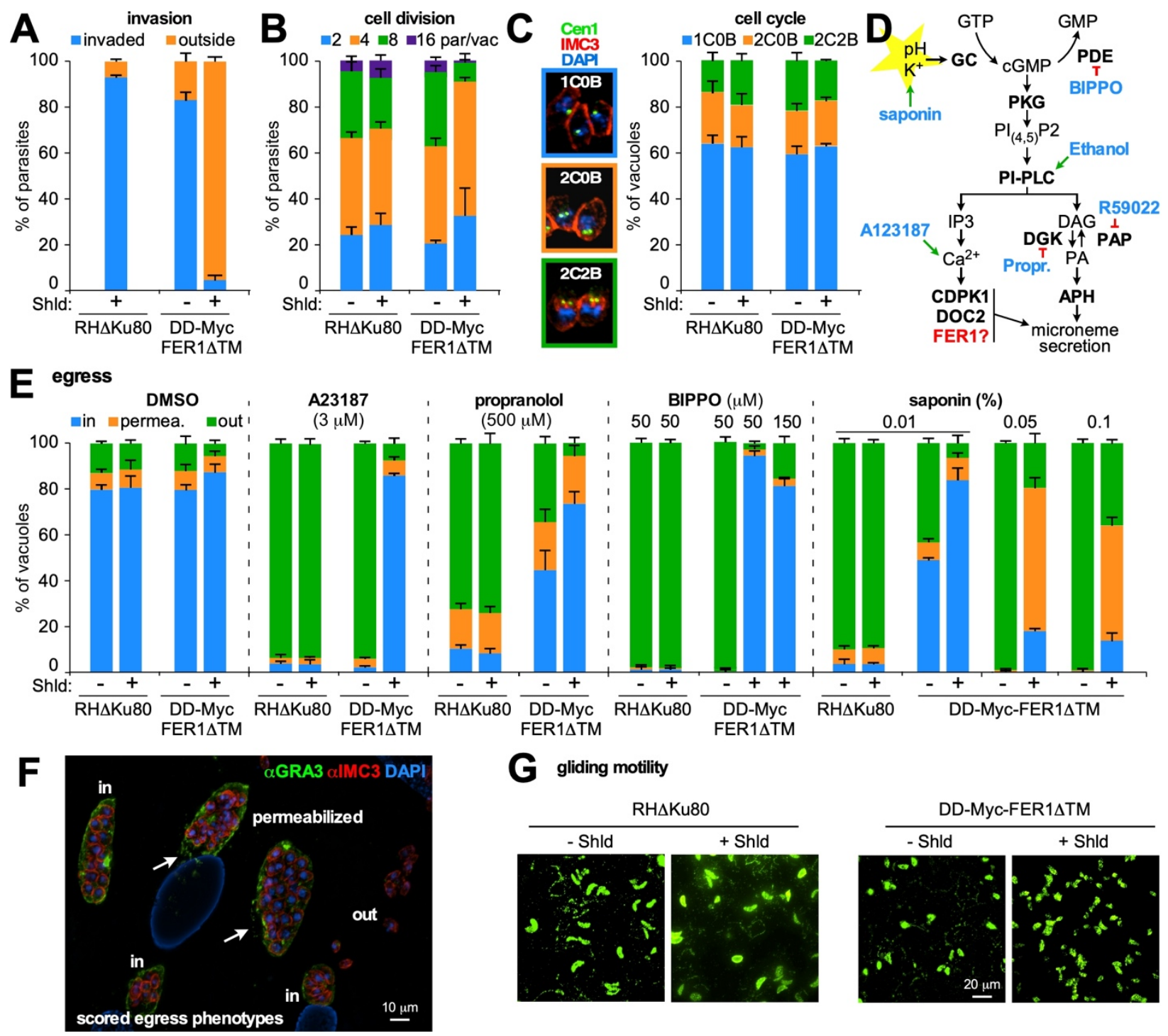

G gliding motility
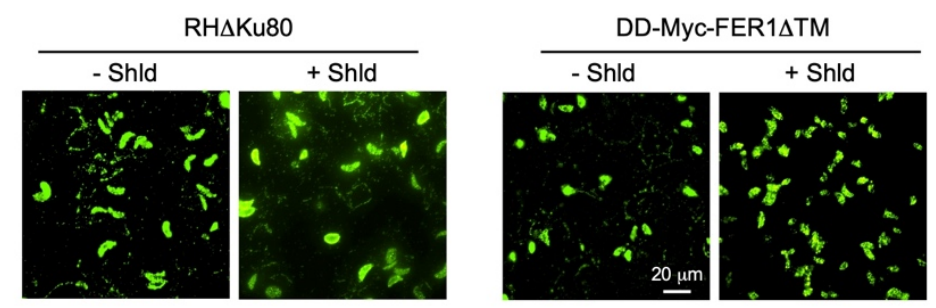

H
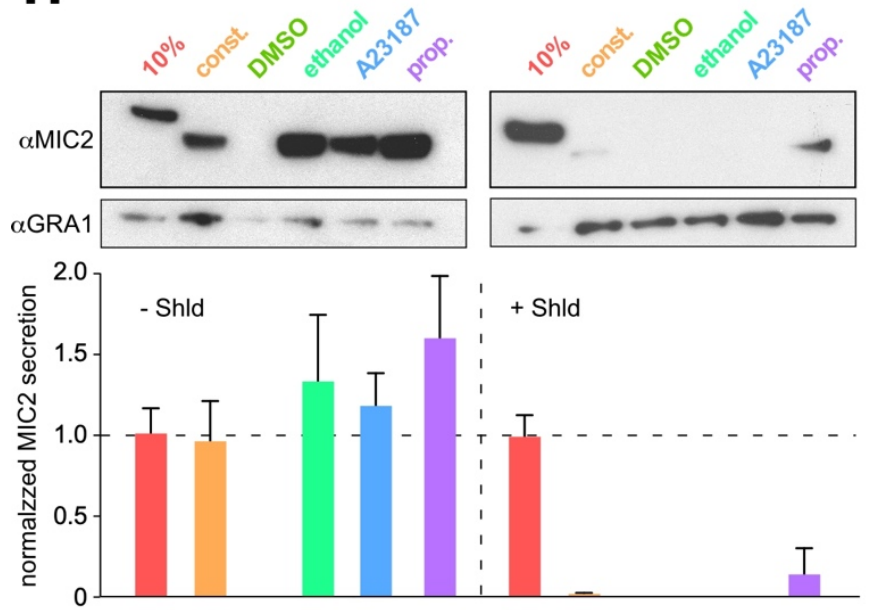
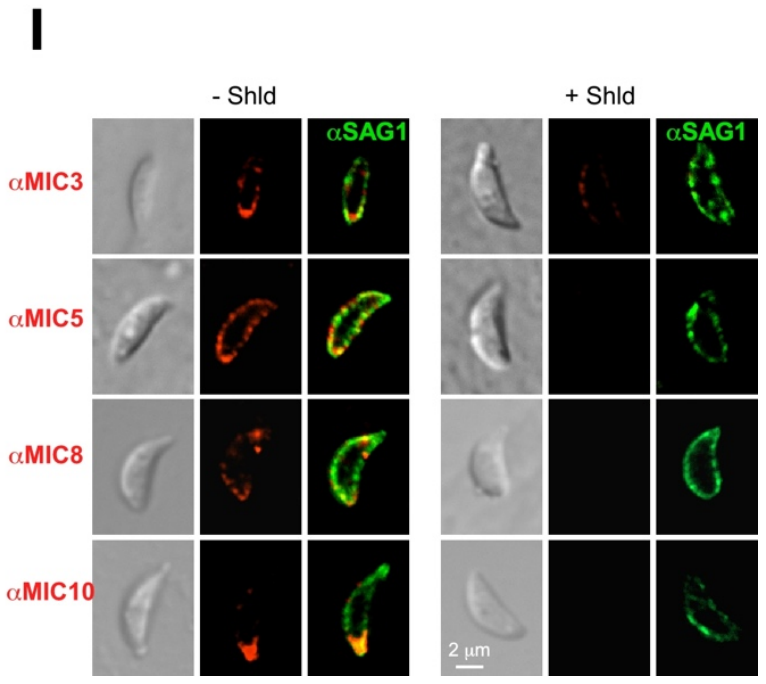
Figure 3. Phenotypic characterization of parasites overexpressing DD-Myc-FER1 $\Delta$ TM. A.

1180 Red-green invasion assay data reveal an invasion defect. B, C. Cell division and cell cycle

1181 progression analysis show that overexpression of DD-Myc-FER1 $\Delta$ TM results in slightly slower

1182 reproduction rates (B), however a significant delay in cell cycle was not detected (C). Examples

1183 of the cell cycle stages quantified in the left of panel $\mathrm{C}$ are shown on the right. Parasites were

1184 allowed to invade for $2 \mathrm{hrs}$ upon which $1 \mu \mathrm{M}$ Shield-1 was added for $18 \mathrm{hrs} . \mathrm{p}=0.031$ ( $t$-test)

1185 accumulation of parasite in the 4-cells/vacuole stage. D. Schematic overview of signaling toward

1186 microneme secretion and egress, highlighting pharmacological agents acting on various events.

1187 E, F. Induced egress assays. Parasites grown for $30 \mathrm{hrs}$ in fibroblasts and induced for $18 \mathrm{hrs}$ with

$11881 \mu \mathrm{M}$ Shield-1 were triggered for egress with the pharmacologicals as indicated, fixed and

1189 stained with $\alpha$-IMC3 (parasite cortex) and $\alpha$-GRA3 (PVM) sera and scored for status of vacuole

1190 permeabilization and/or egress (F; representative image; arrows mark holes in the PVM of

1191 permeabilized vacuoles). $n=3 \pm$ std. Parasites were not under Shield-1 pressure during the 5 min

1192 pharmacological incubation. G. Trail assay using $\alpha-S A G 1$ serum to assess gliding motility

1193 capacity reveals that DD-Myc-FER1 $\triangle$ TM parasites are unable to glide. Parasites were induced

1194 for $18 \mathrm{hrs} \pm 1 \mu \mathrm{M}$ Shield-1, mechanically released from host cells and kept under $1 \mu \mathrm{M}$ Shield-1

1195 throughout the $30 \mathrm{~min}$ gliding experiment at $37^{\circ} \mathrm{C}$. H. Assessment of microneme secretion by

1196 western blot detection of MIC2 released in the supernatant under various triggers. Parasites were

1197 induced $18 \mathrm{hrs}$ with $1 \mu \mathrm{M}$ Shield-1 and harvested by physical release from the host cell. $10 \%$ :

$119810 \%$ of total lysate; const.: $1 \mathrm{hr}$ constitutive secretion at $37^{\circ} \mathrm{C}$ in absence of secretagogue; $1 \%$

1199 ethanol; $2 \mu \mathrm{M}$ A23187; $500 \mu \mathrm{M}$ propranolol. DMSO is the vehicle control for A23187. Induced

1200 secretion for $5 \mathrm{~min}$ at $37^{\circ} \mathrm{C}$. Bottom of panel represents quantified secretion normalized to the

1201 GRA1 signal and to the $10 \%$ loading control for each condition. $n=3 \pm$ std. Parent line controls in

1202 Supplementary Fig S1. Parasites were not under Shield-1 pressure during secretion assay. I.

1203 Secretion of the Rab5/A-dependent microneme population was assessed by IFA on non-

1204 permeabilized parasites induced for $18 \mathrm{hrs} \pm 1 \mu \mathrm{M}$ Shield-1, mechanically released, and exposed

1205 to fresh host cells for $5 \mathrm{~min}$ at $37^{\circ} \mathrm{C}$. Parasites were not under Shield-1 pressure during assay. 
bioRxiv preprint doi: https://doi.org/10.1101/2020.04.27.063628; this version posted April 28, 2020. The copyright holder for this preprint (which was not certified by peer review) is the author/funder, who has granted bioRxiv a license to display the preprint in perpetuity. It is made available under aCC-BY-NC-ND 4.0 International license.

1206 Figure 4

A DD-Myc-FER1 $\triangle T M$

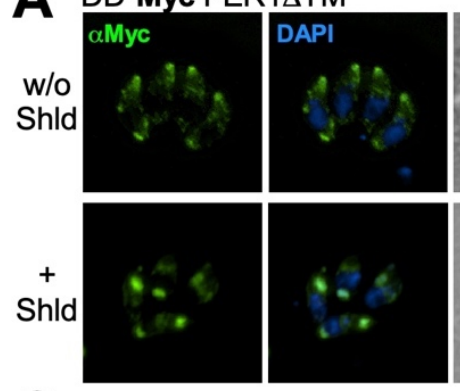

C w/o Shld
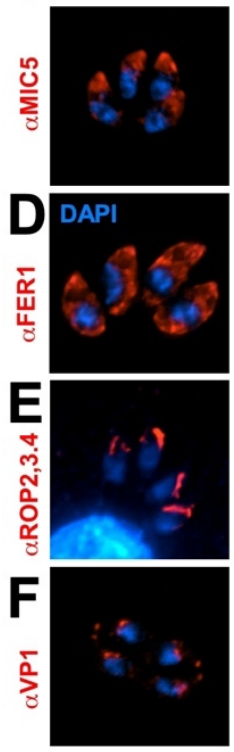

H

DD-Myc

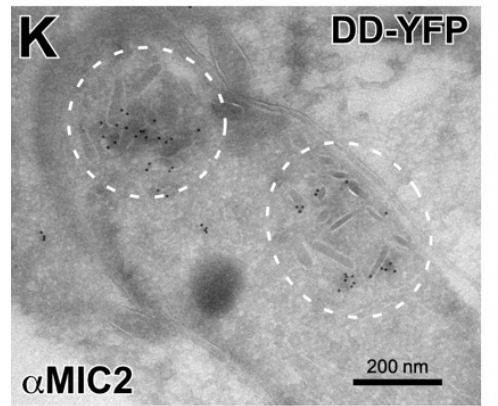

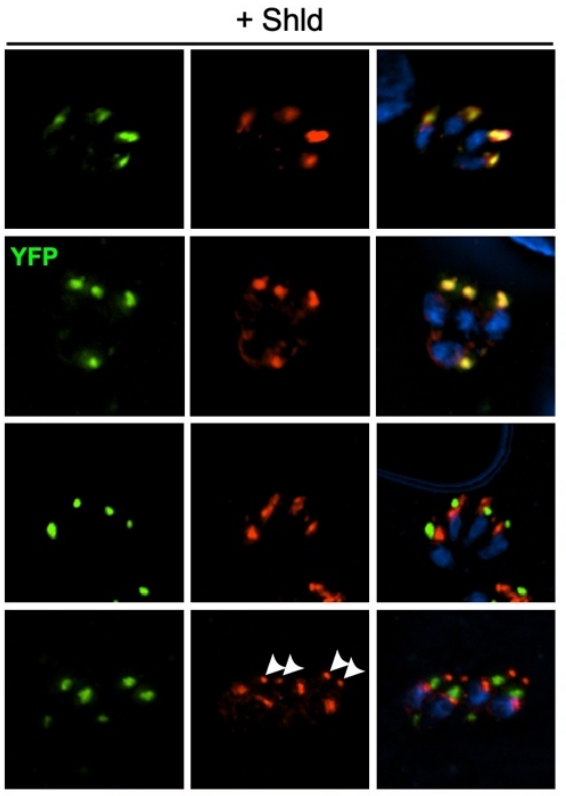

G w/o Shld
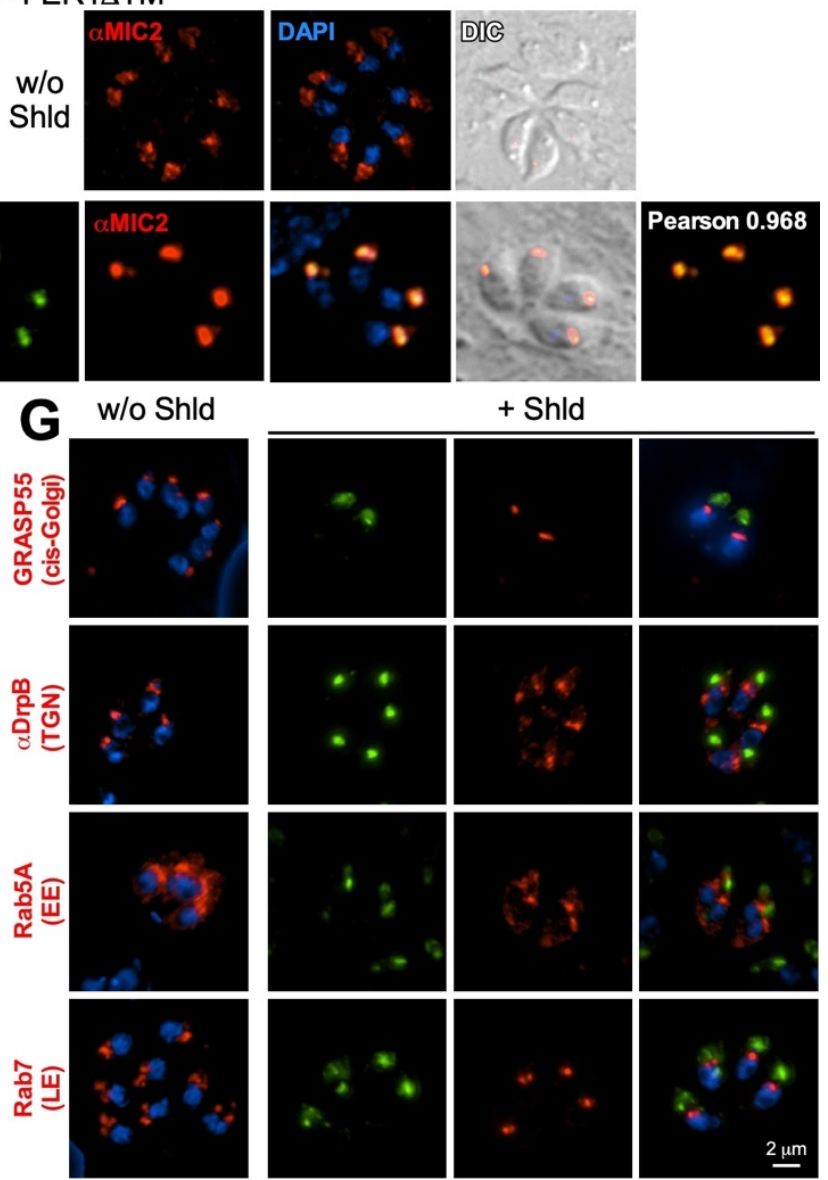

+ Shld
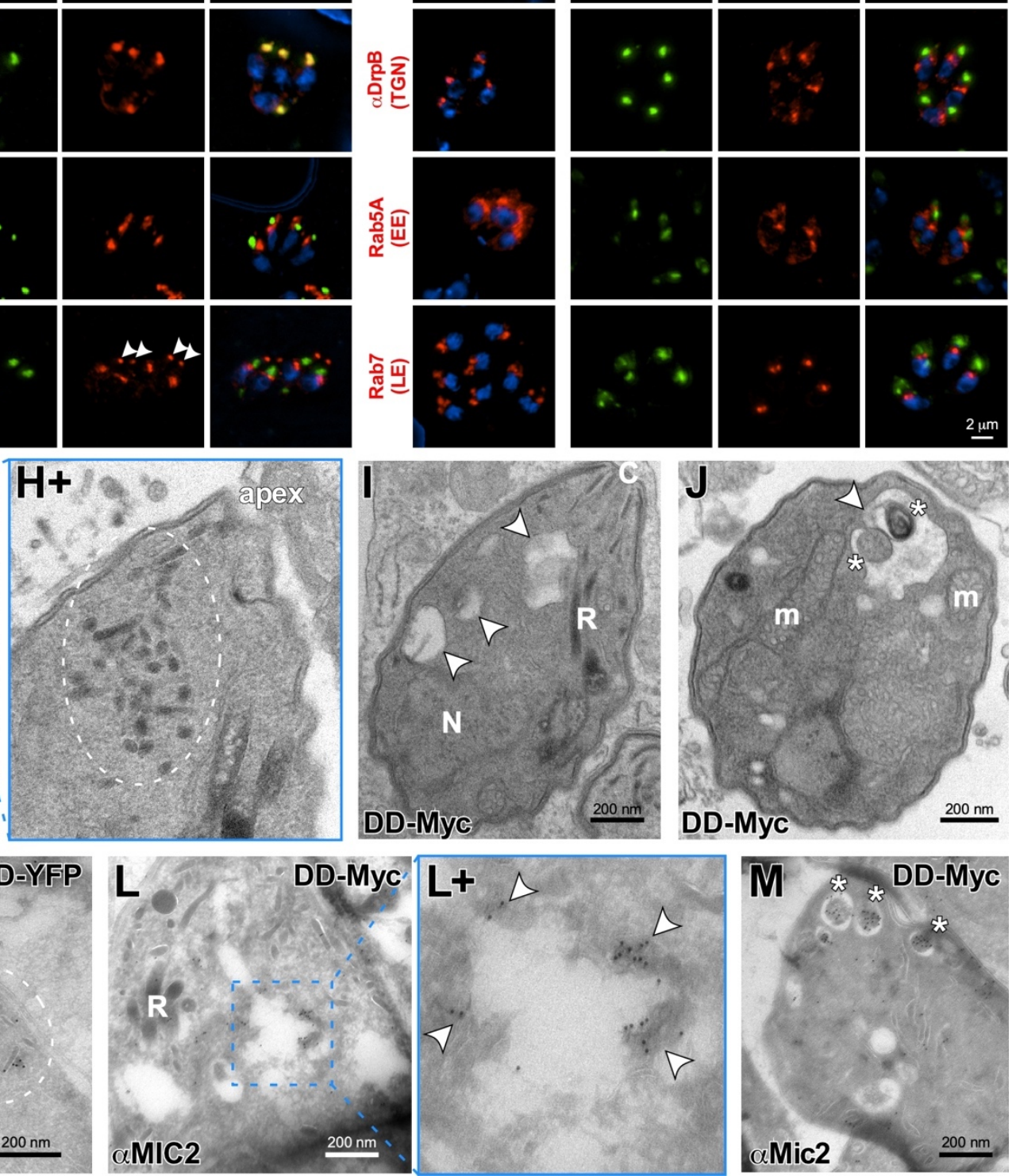
1208 Fig 4. Overexpression of dominant negative FER1 $\Delta$ TM constructs result in microneme

1209 mislocalization. A, B. Overexpression of DD-Myc-FER1

1210 leads to accumulation of microneme protein, visualized with $\alpha$-MIC2, in a central, apical

1211 location. YFP and MIC2 co-localization was assesses by Pearson correlation. C. Microneme

1212 proteins of the Rab5A/C-dependent trafficking pathway, visualized with $\alpha$-MIC5, also

1213 accumulate in the FER1 compartment. D. $\alpha$-FER1 serum confirms exclusive accumulation in the

1214 microneme protein compartment. E. ROP proteins do not accumulate and rhoptry morphology is

1215 normal. F. Co-localization of VP1 and the YFP accumulation is not detected. Note the apical

1216 VP1 localization is still present (arrowheads). G. Markers for cis Golgi, trans-Golgi network

1217 (TGN) as well as early (EE) and late (LE) endosome markers localize normally and do no co-

1218 localize with the YFP accumulation. In all IFA experiments parasites were treated with $1 \mu \mathrm{M}$

1219 Shield-1 for $18 \mathrm{hrs}$; results with additional independent markers for the same compartments are

1220 provided in Supplementary Fig S2. H-J. TEM of DD-Myc-FER1 $\Delta$ TM overexpressing parasites

1221 induced for 16 hrs with $1 \mu \mathrm{M}$ Shield-1. N, nucleus; R, rhoptries; m, mitochondrion. Dotted circle

1222 marks atypical accumulation of microneme organelles in the apical end. Arrowheads mark

1223 enlarged vacuoles, sometimes with *-marked accumulations inside. K-M. IEM with MIC2

1224 antibody (10 nm gold particles) of DD-Myc-FER1 $\Delta \mathrm{TM}$ or of DD-YFP-FER1 $\Delta \mathrm{TM}$

1225 overexpressing parasites induced for either $7 \mathrm{hrs}$ with $3 \mu \mathrm{M}$ Shield-1 (K,M) or 16 hrs with $1 \mu \mathrm{M}$

1226 Shield-1 (L). Dotted circles mark atypical microneme accumulations in the cytosol. R, rhoptries.

1227 Arrowheads mark MIC2 signal at the edge of an enlarged vacuole. Asterisks mark accumulations

1228 inside vacuoles containing MIC2 protein. 
bioRxiv preprint doi: https://doi.org/10.1101/2020.04.27.063628; this version posted April 28, 2020. The copyright holder for this preprint (which was not certified by peer review) is the author/funder, who has granted bioRxiv a license to display the preprint in perpetuity. It is made available under aCC-BY-NC-ND 4.0 International license.

\section{Figure 5}

A
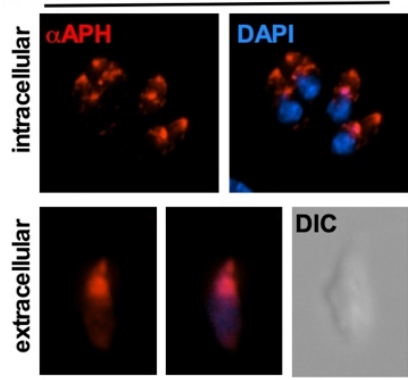

C

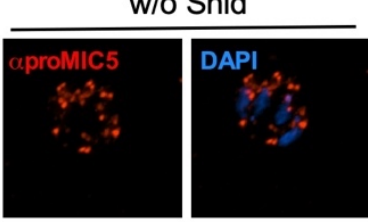

$\mathbf{D}$
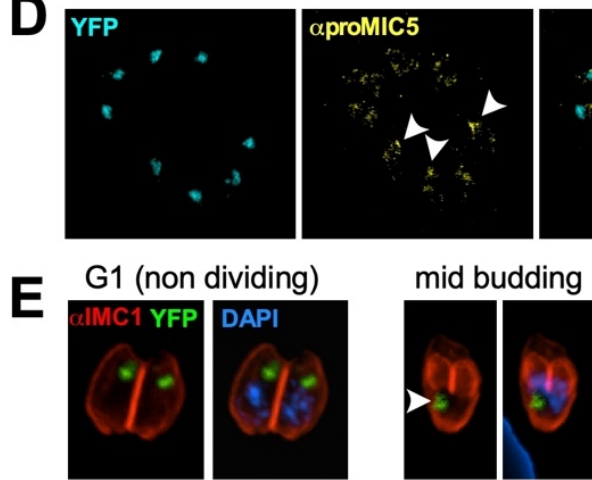

$\mathbf{F}$
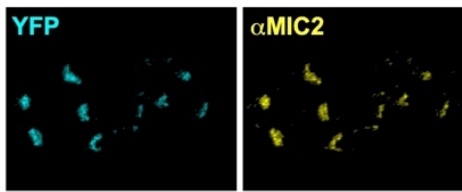

H

Time laps of microneme mislocalization
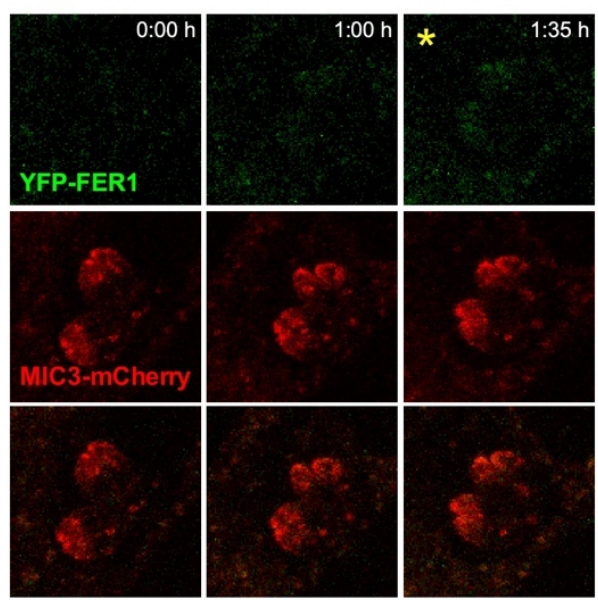

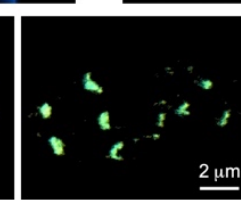

+ Shld
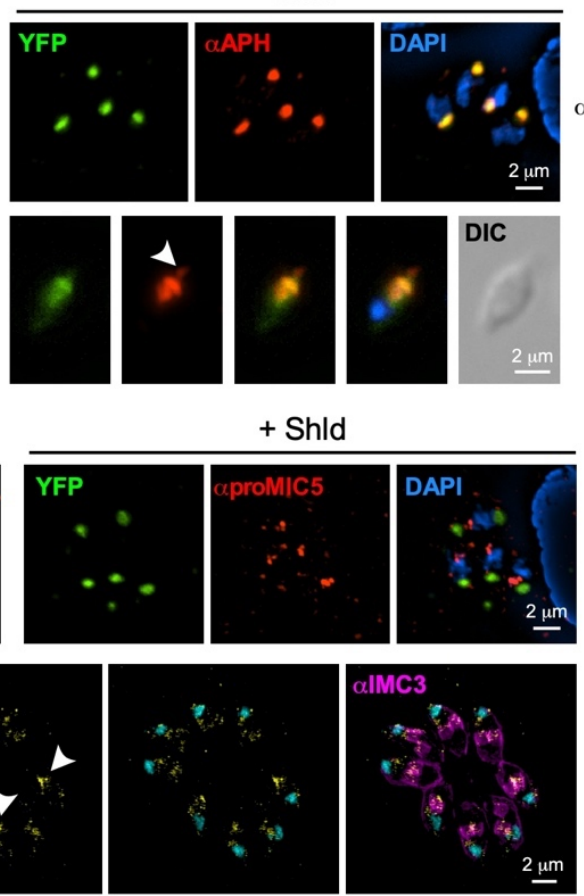

late budding
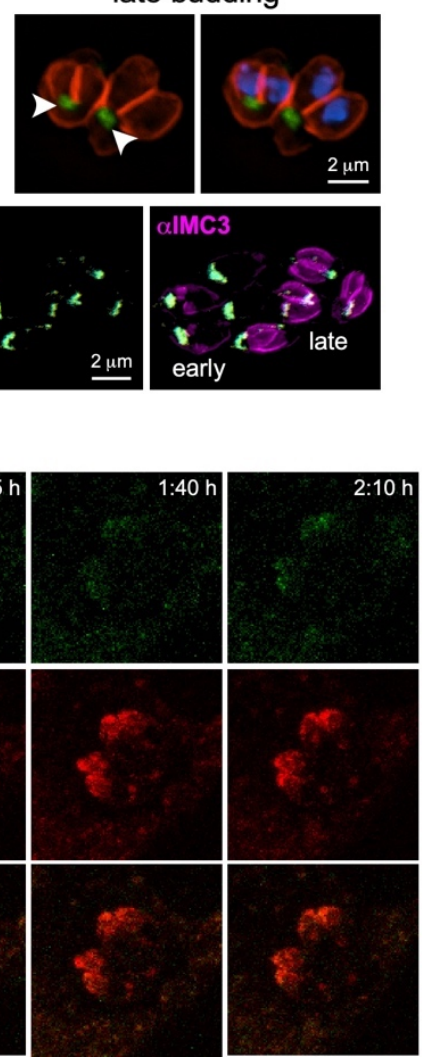

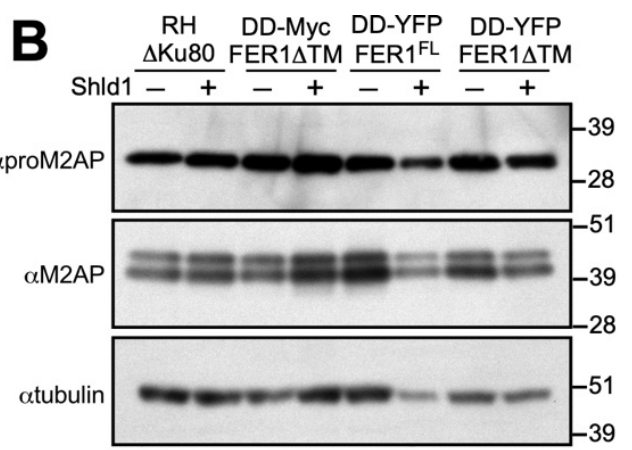

G

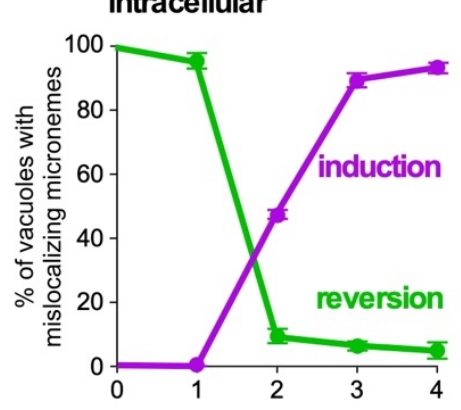

extracellular

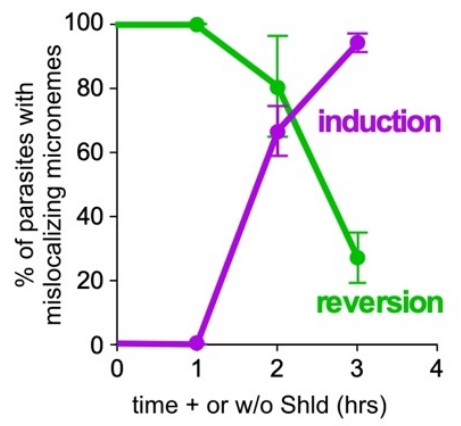

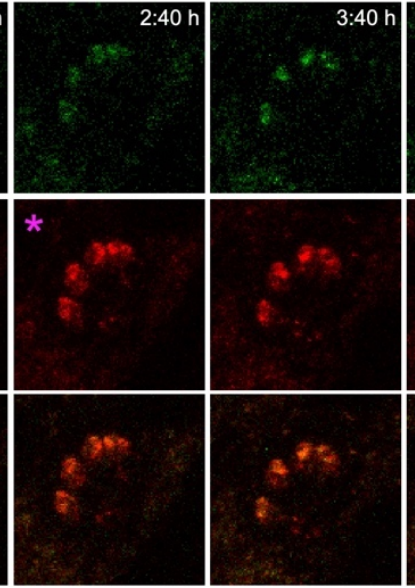

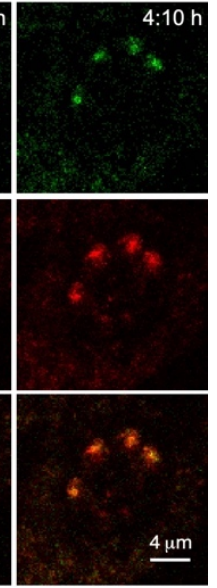


1232 Figure 5. Microneme trafficking dynamics upon DD-YFP-FER1 $\Delta$ TM overexpression. In all

1233 IFA experiments parasites were treated with $1 \mu \mathrm{M}$ Shield-1 for $18 \mathrm{hrs}$. A. Mislocalized

1234 micronemes are coated with the mature microneme marker APH in both intracellular (top) and

1235 extracellular (bottom) parasites. Arrowhead marks APH signal in the conoid where YFP signal is

1236 absent. B. Normal maturation by pro-peptide processing in the ELC-PLV compartment of

1237 microneme proteins in induced and various control parasites as indicated was demonstrated by

1238 western blot using antiserum against the pro-peptide of M2AP ( $\alpha$-proM2AP) and antiserum

1239 against the mature section of the protein ( $\alpha$-M2AP). $\alpha$-tubulin serves as loading control. C. IFA

1240 with $\alpha$-proMIC5 revealed that microneme accumulation is not due to arrested trafficking since

1241 proMIC5 is only observed in the ELC-PLV compartment in newly forming daughter buds. D.

1242 Induced mutants co-stained with YFP, proMIC5, and IMC3 antiserum to track the timing and

1243 localization of proMIC5 processed as indicated. Arrowheads mark the proMIC5 compartment

1244 within budding daughter buds. Note that DD-YFP-FER1 $\triangle$ TM is exclusively present in the

1245 mother parasites and does not localize to the budding daughters. E. Induced mutants co-stained

1246 with IMC1 antiserum to track division stages as indicated. Arrowheads mark the mother

1247 parasite's YFP accumulation migrating into a basal direction during progression of daughter

1248 budding. Note the absence of YFP in the daughter buds.

1249 F. Induced mutants co-stained with YFP, MIC2, and IMC3 antisera to track the localization of

1250 mature MIC2 protein through cell division. Note the consistent colocalization of DD-YFP-

1251 FER1 $\triangle \mathrm{TM}$ with MIC2 throughout the division stages, indicating that the daughter buds never

1252 assemble mature micronemes. G. Time courses of the incidence of vacuoles or individual

1253 parasites with mislocalizing micronemes in intracellular and extracellular parasites, respectively,

1254 visualized through $\alpha$-MIC2 IFA. At least 100 vacuoles or parasites were counted per time point.

$1255 \mathrm{n}=3 \pm$ std. In reversion experiments, intracellular parasites were induced for 18 hrs with Shield-1.

1256 H. Select panels from time lapse experiment with DD-YFP-FER1 $\Delta T M$ parasites co-transfected

1257 with MIC3-mCherry to track microneme localization dynamics. At $\mathrm{t}=0,2 \mu \mathrm{M}$ Shield-1 was

1258 added. The first time point at which the piling up of YFP-FER1 could be convincingly observed

1259 is marked with a yellow asterisk; the first time where MIC3-mCherry can be seen re-localizing

1260 from the apical cortex to the central apical localization co-localizing with YFP-FER1 is marked

1261 with a purple asterisk. Panels from supplementary movie S1. 
bioRxiv preprint doi: https://doi.org/10.1101/2020.04.27.063628; this version posted April 28, 2020. The copyright holder for this preprint (which was not certified by peer review) is the author/funder, who has granted bioRxiv a license to display the preprint in perpetuity. It is made available under aCC-BY-NC-ND 4.0 International license.

1262 Figure 6

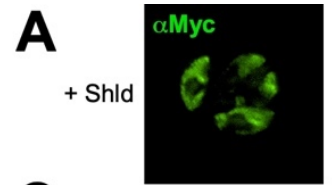

C
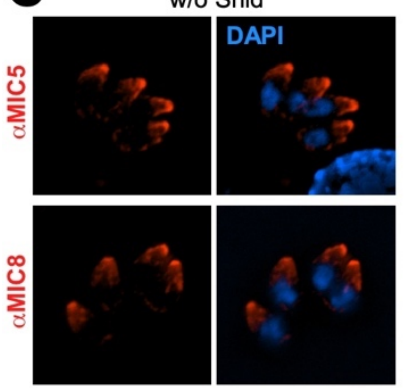

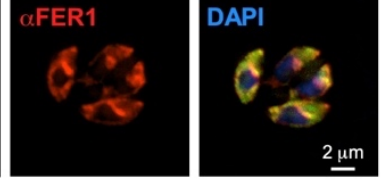

+ Shld
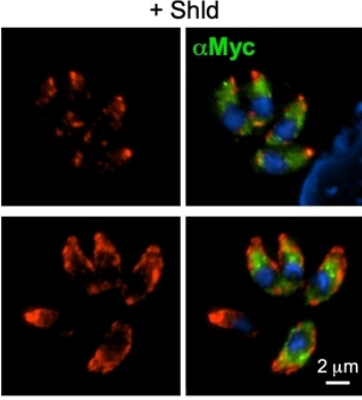

B
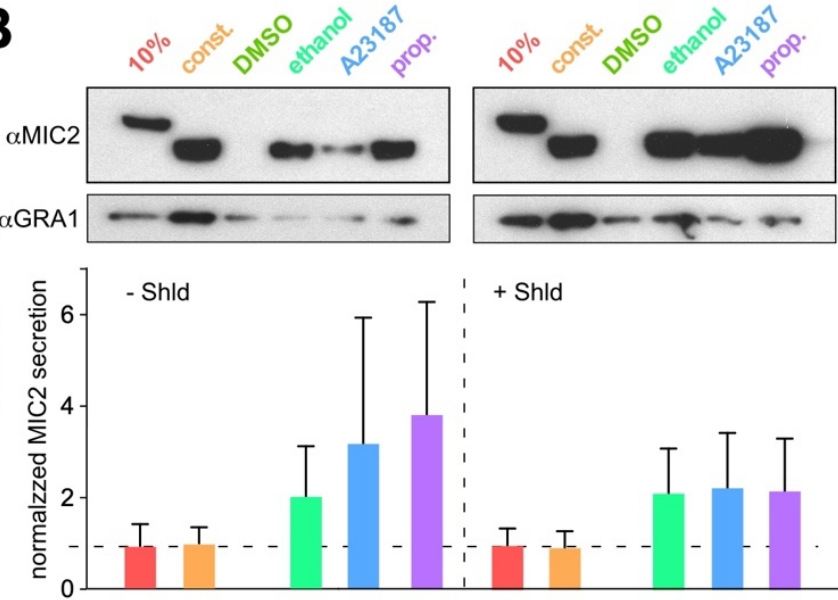

D

$\mathrm{RH} \Delta \mathrm{Ku} 80$
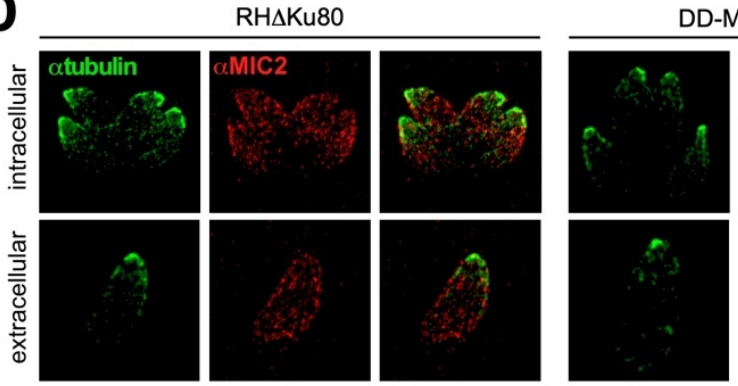

D-Myc-FER ${ }^{\text {FL }}$ w/o Shld
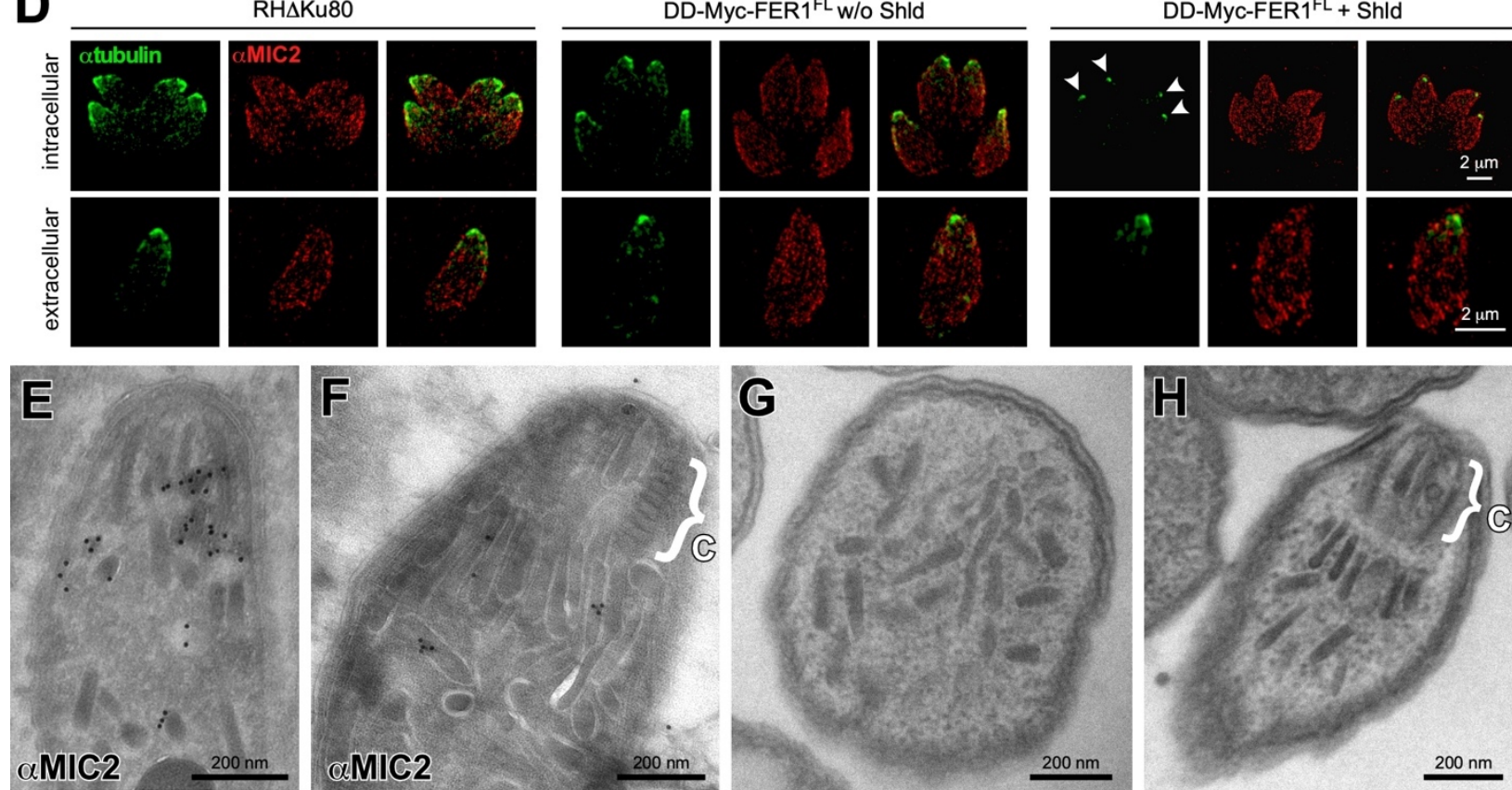

aMIC2
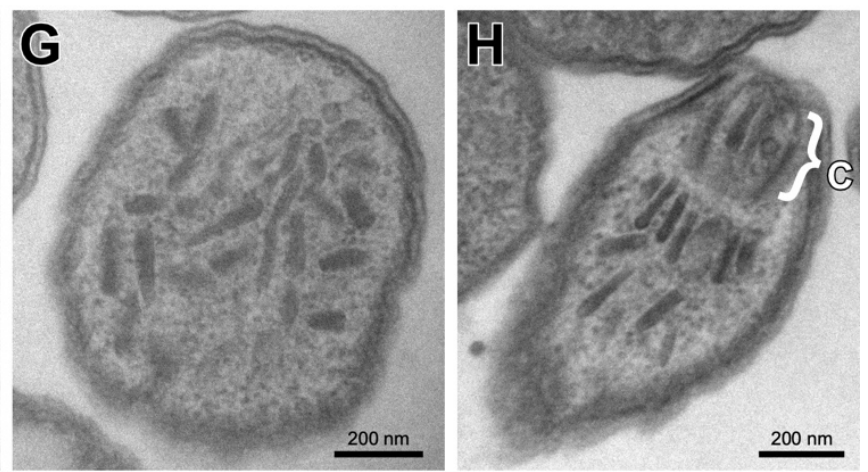

Shield induced microneme secretion

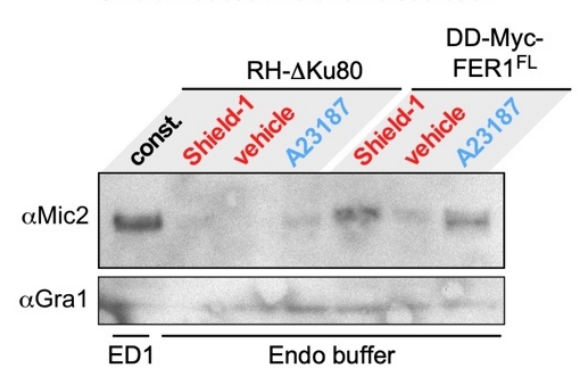

K

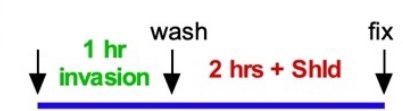

I
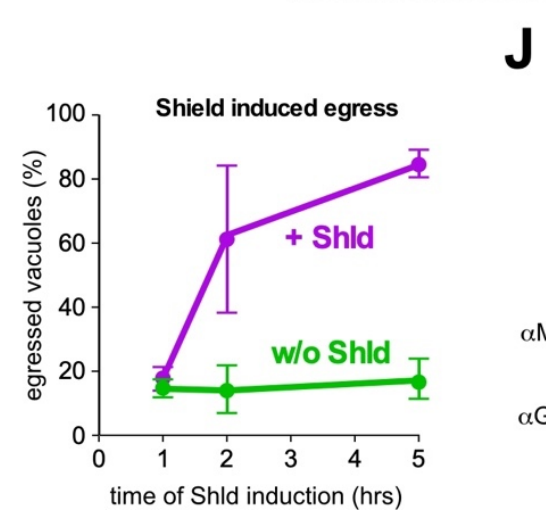

$$
\text { time of Shld induction (hrs) }
$$

1264

1265 


\section{Figure 6. DD-Myc-FER1 ${ }^{\mathrm{FL}}$ overexpression results in apical microneme migration and a}

1267 burst of signaling-independent microneme release. A. Co-staining of $\alpha$-Myc and $\alpha$-FER1 sera

1268 by IFA shows that overexpressed DD-Myc-FER $1^{\mathrm{FL}}$ localizes to the cytoplasm. Total projection

1269 of deconvolved image is shown. B. Assessment of microneme secretion by western blot through

1270 MIC2 release in the supernatant under various triggers. Parasites were induced 6 hrs with $1 \mu \mathrm{M}$

1271 Shield-1 and harvested by physical release from the host cell. 10\%: 10\% of total lysate; const.: 1

$1272 \mathrm{hr}$ constitutive secretion at $37^{\circ} \mathrm{C}$ in absence of secretagogue; $1 \%$ ethanol; $2 \mu \mathrm{M} \mathrm{A} 23187 ; 500 \mu \mathrm{M}$

1273 propranolol. DMSO is the vehicle control for A23187. Induced secretion for 5 min at $37^{\circ} \mathrm{C}$.

1274 Bottom of panel represents quantified secretion normalized to the GRA1 signal and to the $10 \%$

1275 loading control for each condition. $n=3 \pm$ std. Parent line controls in Supplementary Fig S1.

C. Immunofluorescence of DD-Myc-FER $1^{\mathrm{FL}}$ co-stained with $\alpha$-MIC5 and $\alpha$-MIC8 and $\alpha$-FER1

1277 shows that this Rab5A/C-dependent microneme population becomes scattered upon phenotype

1278 induction, although an extreme apical focal point remains. D. Super-resolution SIM microscopy

1279 of wild-type and DD-Myc-FER $1^{\mathrm{FL}}$ co-stained with $\alpha$-MIC2 and $\alpha$-Tg $\beta$-tubulin further details

1280 apical microneme translocation in intracellular parasites upon Shield-1 induction (arrowheads).

1281 In extracellular parasites an increased apical accumulation of micronemes is seen across control

1282 and mutant parasites regardless of phenotype induction. E, F. IEM of DD-Myc-FER1 $1^{\mathrm{FL}}$

1283 overexpressing parasites stained with MIC2 antibody (10 nm gold particles) induced for $16 \mathrm{hrs}$

1284 with $1 \mu \mathrm{M}$ Shield-1. MIC signal localizes to apically accumulated micronemes which display a

1285 stretched or extended morphology. Accolade bracket marks conoid (c). G, H. TEM of

1286 extracellular DD-Myc-FER $1^{\mathrm{FL}}$ overexpressing parasites induced for 3 hrs with $2 \mu \mathrm{M}$ Shield-1.

1287 Cross section in J shows the extended feature or the densely packed microneme organelles,

1288 whereas K shows the radial micronemes just below the conoid, again with a slightly stretched or

1289 extended appearance. Accolade bracket marks conoid (c). I. Time course of Shield-1 Induced

1290 egress. Parasites grown for $30 \mathrm{hrs}$ in fibroblasts and induced for $1 \mu \mathrm{M}$ Shield-1 for the times as

1291 indicated, fixed with 100\% methanol and stained with $\alpha$-Myc, $\alpha$-MIC8 and DAPI. Intact

1292 vacuoles per field were scored as proxy for egress. $n=3 \pm$ std. J. Shield-1 induced microneme

1293 secretion in Endo buffer. Western blot of MIC2 release in the supernatant; GRA1 as control.

1294 Const.: Constitutive $1 \mathrm{hr}$ at $37^{\circ} \mathrm{C}$ in standard ED1 culture medium. In intracellular conditions

1295 mimicking Endo buffer, parasites were induced with $1 \mu \mathrm{M}$ Shield- 1 for $2 \mathrm{hrs}$ at $37^{\circ} \mathrm{C}$; vehicle

1296 represent the solvent of the Shield-1 stock (0.1\% ethanol end concentration). A23187 (1 $\mu \mathrm{M})$ 
1297 was added for $5 \mathrm{~min}$ in the end of the $2 \mathrm{hr}$ window and is additive to the constitutive secretion.

1298 K. Modified red-green invasion assay followed by Shield-1 induction. Top schematic shows

1299 parasites were allowed to invade for $1 \mathrm{hr}$ min at $37^{\circ} \mathrm{C}$ followed by a wash to remove non-invaded

1300 parasites and $2 \mathrm{hrs} 1 \mu \mathrm{M}$ Shield-1 induction followed by the red-green invasion assay. Lower

1301 panel shows the relative number of parasites observed outside the host cell, indicating

1302 overexpression of FER1 leads to microneme secretion, egress, and host cell destruction. $\mathrm{n}=4 \pm$ std. 


\section{Figure 7 - FER1 is $\mathbf{C a}^{2+}$ dependendent}

A

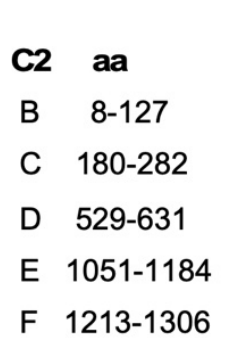

position

\begin{tabular}{cccccc}
\hline $\mathbf{1}$ & $\mathbf{2}$ & $\mathbf{3}$ & $\mathbf{4}$ & $\mathbf{5}$ & binding \\
EIVPN & VPNPY & VLHKY & HKYML & LQSAV & no \\
AGQFS & VLEPY & LWNGQ & NGQDS & AGTLM & no \\
GYDVF & FPDPY & ISESN & ESNSL & SSDVV & Ca $^{2+}$ \\
PPSGA & DIQTY & VNMNG & NMGRL & TDECI & no \\
LDDNS & SISLF & IWNYA & NYALL & STEPI & no \\
& \multicolumn{3}{c}{ strongest Conservation } & &
\end{tabular}

B

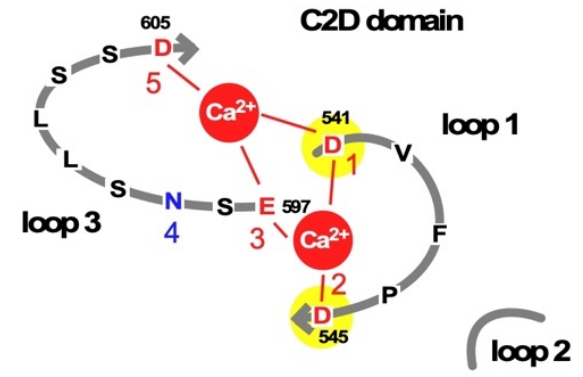

C DD-Myc-FER1 $\triangle T M^{(D 541 A, D 545 A)}$
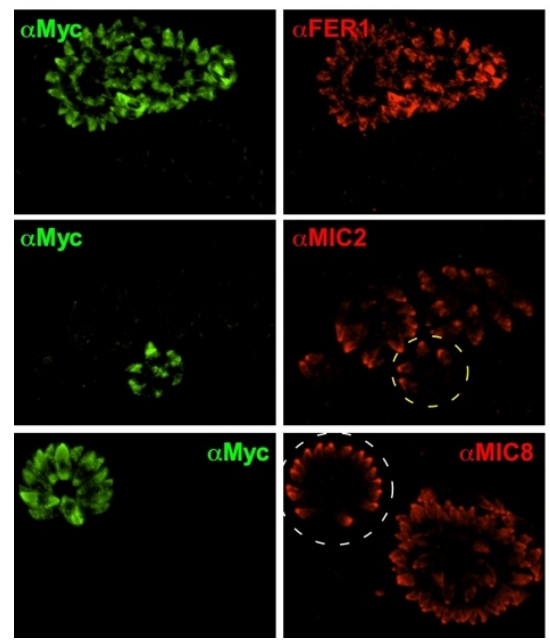
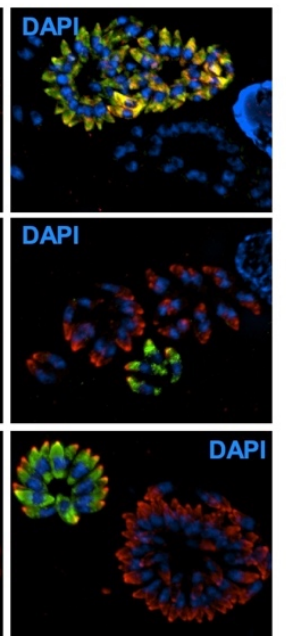
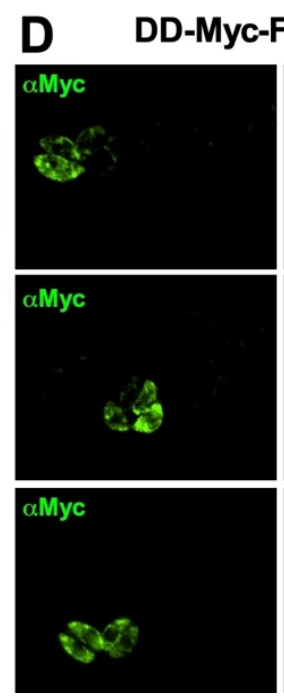

-FER1 ${ }^{\text {FL-(D541A, D545A) }}$
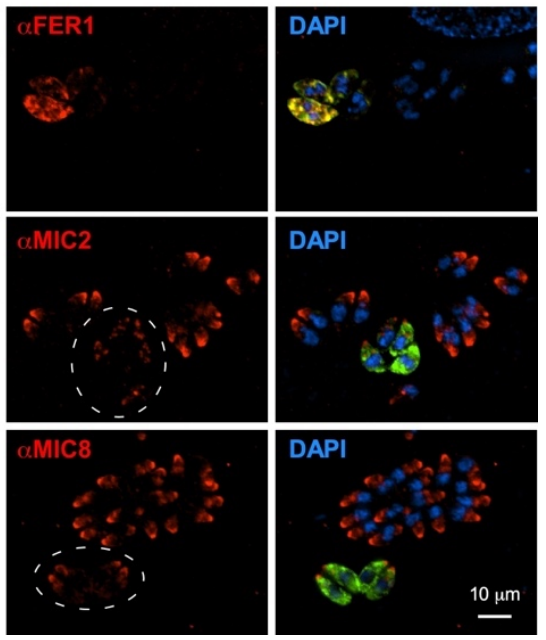

Figure 7. FER1-mediated trafficking of micronemes relies on predicted $\mathrm{Ca}^{2+}$-binding residues. A. Sequence analysis of the five conserved key positions (\#1-5) in the C2A-F domain

1309 loops interfacing with $\mathrm{Ca}^{2+}$ [104]. D or E residues (red) stabilize $\mathrm{Ca}^{2+}, \mathrm{N}$ or Q (bleu) are expected

1310 to support phospholipid binding. Positions 2, 3, and 4 shaded in grey are more strongly

1311 conserved than positions 1 and 5. Yellow highlighted residues were mutated to A to abolish the

1312 predicted $\mathrm{Ca}^{2+}$-binding capacity in the $\mathrm{C} 2 \mathrm{D}$ domain resulting in the mutant FER $1^{\text {(DD541,545AA) }}$

1313 allele. B. Models of the C2D domain loops and putative $\mathrm{Ca}^{2+}$ binding capacity. Yellow

1314 highlighted residues as in panel A. C, D. Transient overexpression DD-Myc-

1315 FER1 $\Delta \mathrm{TM}^{(\mathrm{D} 541 \mathrm{~A}, \mathrm{D} 545 \mathrm{~A})}$ DD-Myc-FER1 ${ }^{\mathrm{FL}-(\mathrm{D} 541 \mathrm{~A}, \mathrm{D} 545 \mathrm{~A})}$, respectively, co-stained for Myc, FER1,

1316 MIC2 and MIC8, as indicated. Each panel contains transfected (Myc positive) and non-

1317 transfected (Myc negative) parasite examples. Note that due to the high level of overexpression 
1318 the FER1 signal in non-transfected parasites is below the detection limit under these conditions.

1319 Following electroporation, parasites were allowed to invade for 2 hrs before $1 \mu \mathrm{M}$ Shield-1

1320 induction for $24 \mathrm{hrs}$. Yellow dotted circle marks normal MIC morphology while white dotted

1321 circles mark aberrant MIC morphology in vacuoles overexpressing the D541A,545A FER1

1322 alleles as indicated. 


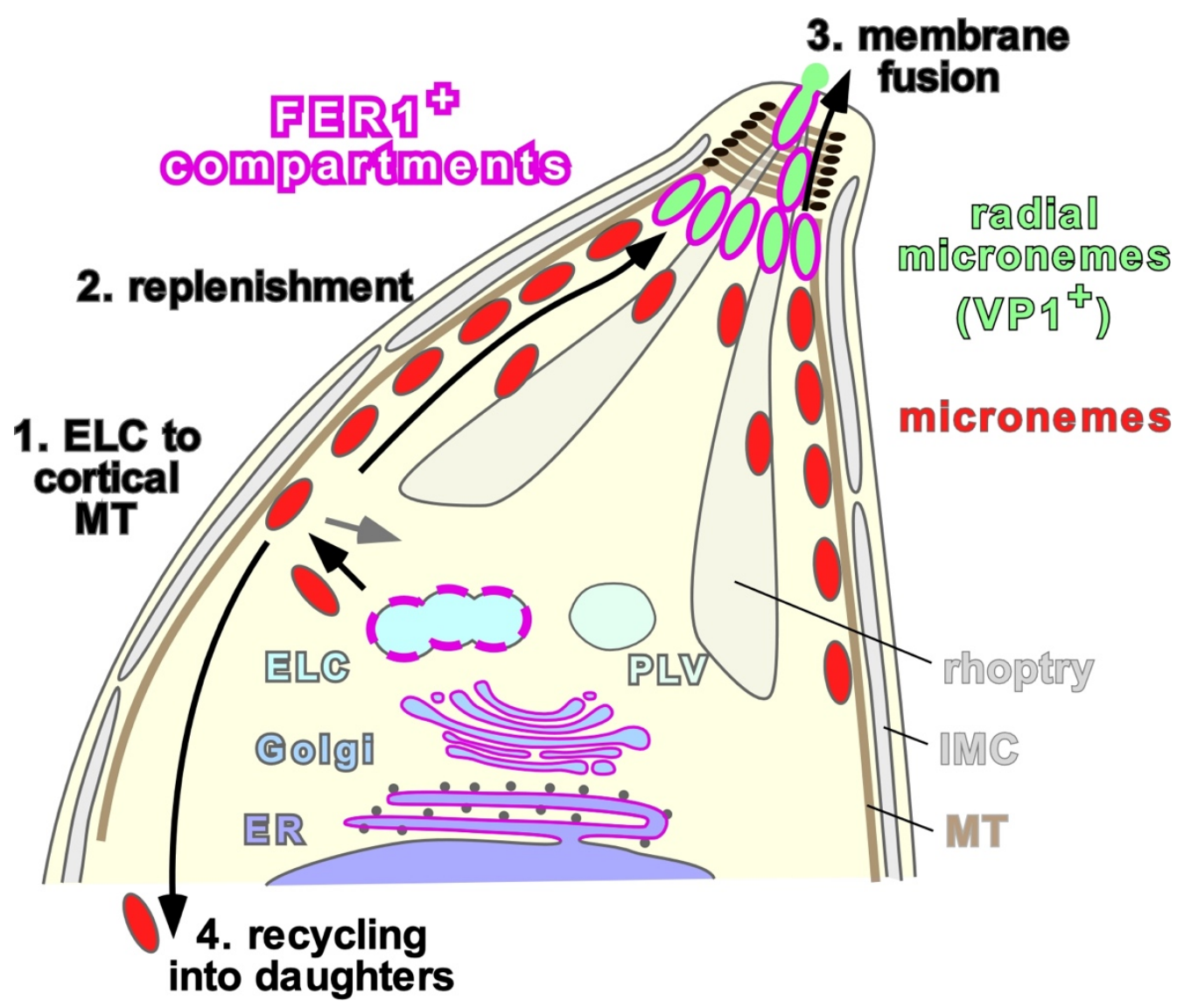

Figure 8. Working model of FER1 mediated microneme events. FER1 mediates the following

1328 trafficking steps: 1. From the ELC to the subpellicular microtubules (actin dependent); 2.

1329 microneme migration along the subpellicular microtubules; 3. Microneme membrane fusion with

1330 the plasma membrane; 4. Recycling of micronemes into the budding daughters (actin dependent).

1331 We hypothesize the radial micronemes represent a readily releasable vesicle pool primed for

1332 secretion by VP1-mediated acidification. MT: microtubules; ELC: endosome-like compartment;

1333 PLV: plant like vacuole or VAC. 


\section{Supplementary data}

1336 Supplementary Movie S1. Time lapse experiment of DD-YFP-FER1

1337 transfected with MIC3-mCherry to track the micronemes. At $\mathrm{t}=0,2 \mu \mathrm{M}$ Shield- 1 was added and 1338 images collected every 5 minutes. Scale bars $80 \mu \mathrm{m}$.

Supplementary movie S2. Time lapse experiment of DD-YFP-FER1 $\Delta$ TM parasites co-

1341 transfected with IMC3-mCherry to track cell division status. At $\mathrm{t}=0,2 \mu \mathrm{M}$ Shield-1 was added 1342 and images collected every 5 minutes. Scale bars $80 \mu \mathrm{m}$.

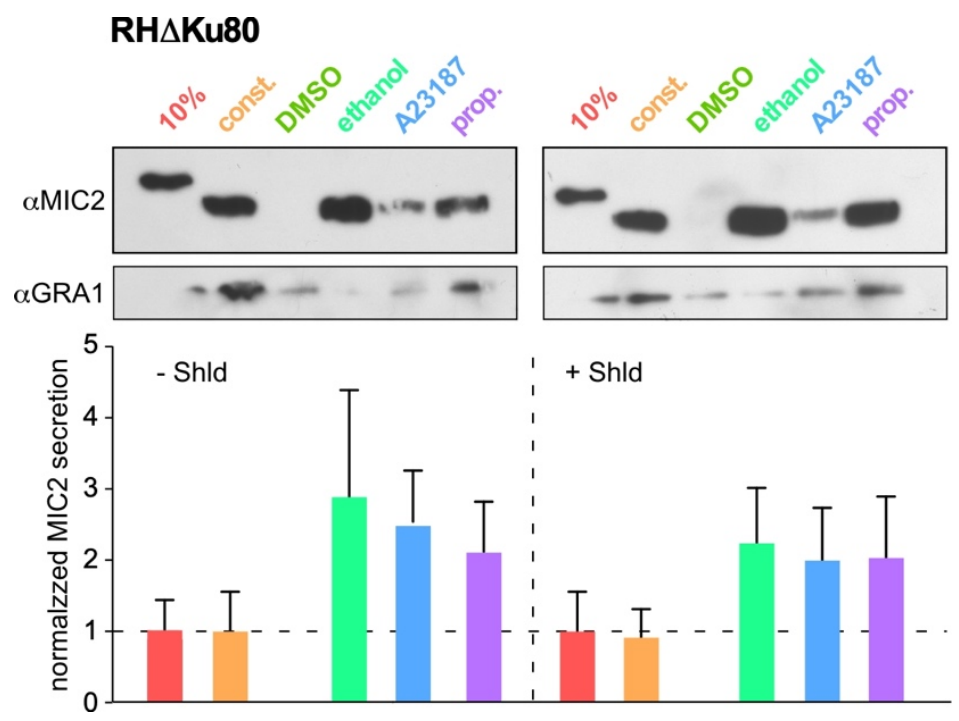

\section{Supplementary Figure S1. Microneme secretion assessment of the RH $\Delta \mathrm{Ku} 80$ parent line}

1350 control. Assessment of microneme secretion by western blotting by detecting MIC2 release in

1351 the supernatant under various triggers. Parasites were induced $18 \mathrm{hrs}$ with $1 \mu \mathrm{M}$ Shield- 1 and

1352 harvested by physical release from the host cell. 10\%: 10\% of total lysate; const.: $1 \mathrm{hr}$

1353 constitutive secretion at $37^{\circ} \mathrm{C}$ in absence of secretagogue; $1 \%$ ethanol; $2 \mu \mathrm{M}$ A23187; $500 \mu \mathrm{M}$

1354 propranolol. DMSO is the vehicle control for A23187. Induced secretion for 5 min at $37^{\circ} \mathrm{C}$.

1355 Bottom of panel represents quantified secretion normalized to the GRA1 signal and to the $10 \%$

1356 loading control for each condition. $n=3 \pm$ std. 


\section{Supplementary Figure S2}

1358
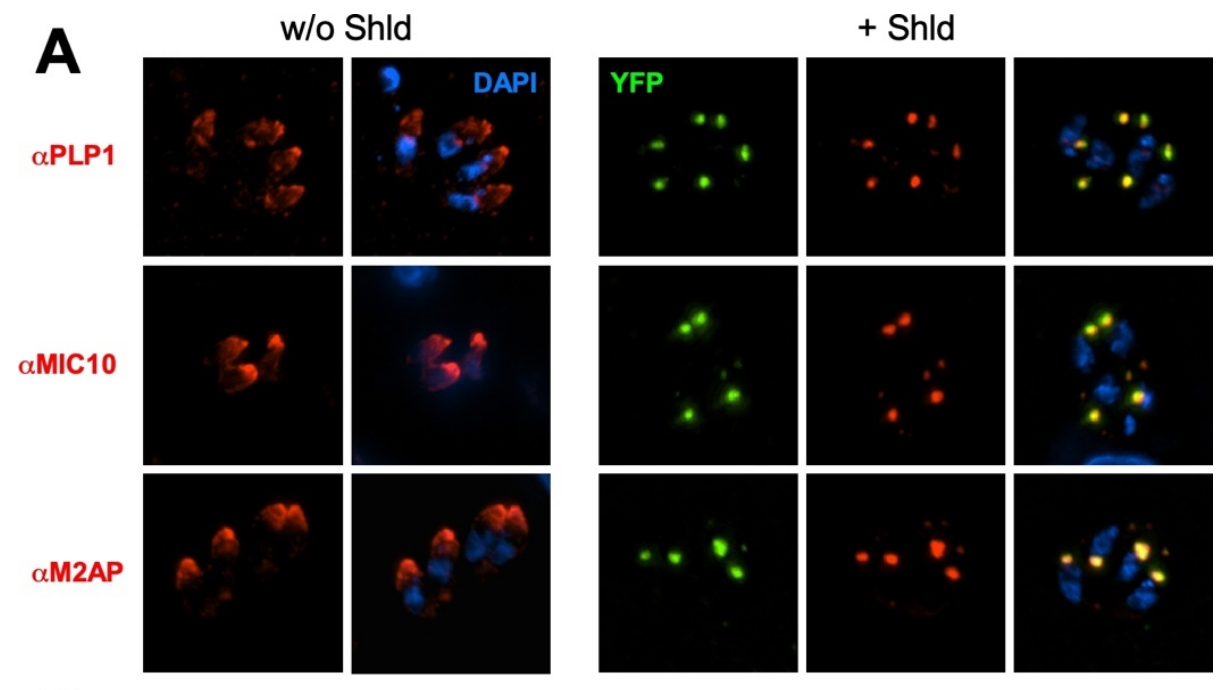

B

$\alpha$ MIC8
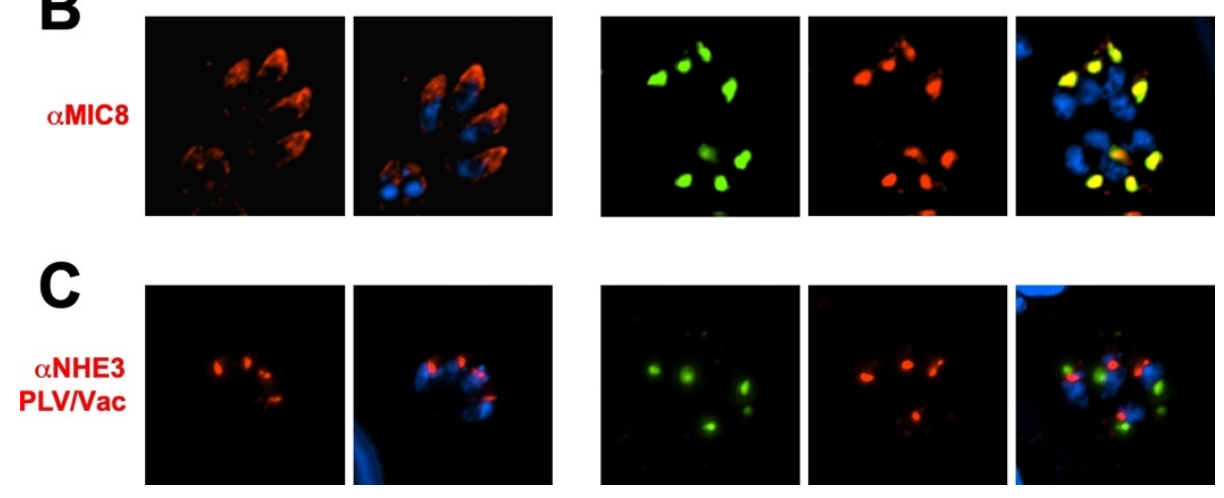

1361 Supplementary Figure S2. Additional localization data in the DD-YFP-FER1 $\Delta$ TM dominant

1362 negative mutant. A. Additional microneme proteins in the MIC2 group. B. Additional protein in

1363 the MIC3/5/8 group. C. NHE3 is a specific marker of the PLV compartment. Parasites were

1364 treated with $1 \mu \mathrm{M}$ Shield-1 for $18 \mathrm{hrs}$. 


\section{Supplementary Figure S3}
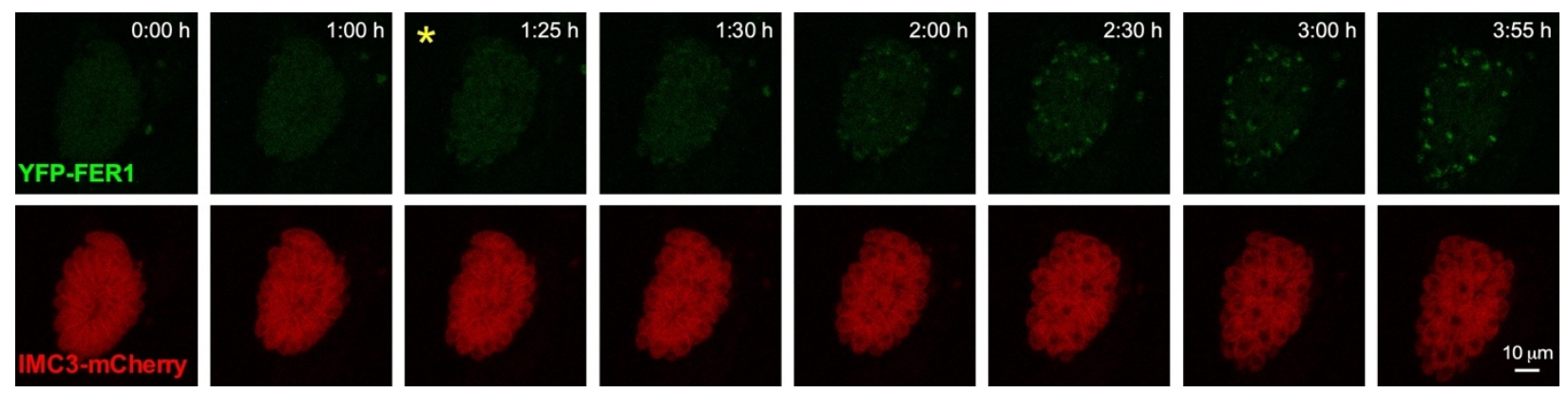

1367 Supplementary Figure S3. Select panels from time lapse experiment of DD-YFP-FER1 $\Delta T M$

1368 parasites co-transfected with IMC3-mCherry to track cell division. At $\mathrm{t}=0,2 \mu \mathrm{M}$ Shield-1 was

1369 added. The first time point at which the piling up of YFP could be convincingly observed is

1370 marked with a yellow asterisk. Panels from supplementary movie S2. 
1371 Supplementary Table S1. Description of oligonucleotides used. Restriction enzyme sites

1372 underlined.

1373

1374

1375

Cloning of tub-YFP-TM(FER1)

1376

1377

1378

1379

\begin{tabular}{lll}
\hline 4786 & FER1-TM-F (Gib) & GCATGGACGAGCTGTACAAGCCTAGGAGCGCCATTATGAGTGGGCTG \\
4788 & $3^{\prime}$ dhfr-Not-R(Gib) & CGAATTGGAGCTCCACCGCGTGGCGGCCGC
\end{tabular}

1380

1381

1382

1383

1384

1385

1386

1387

1388

1389

1390

1391

1392

1393

1394

1395

1396

1397

1398

1399

1400

1401

1402

1403

Cloning of tub-DD-YFP-FER $1^{F L} /$ SagCAT

$\begin{array}{ll}1573 & \text { YFP-109420_F } \\ 1574 & \text { YFP-109420_R }\end{array}$ GGTCCCCTAGGATGGCGGCGAAGGCGATC GGTCCCCCGGGTTATTTGAGGAGAAACATAACAAAGATGACTAGCGC

1635 5xTy_F(avriI) GGACCCCTAGGGAGGTCCATACTAACCAGGATCCACTTGACGGCGAGG

1636 DD_R(MfeI-ECORV) GGACCGATATCTTACAATTGTTCCAGTTTTAGAAGCTCCACACGG

Internal primers used to for FER1 CDS Sanger sequencing

2717 Fer1-RACE-F CGCACCAACGAGAGGCGCTCGCAGCTA

2748 FER1_SeqF2

2749 FER1_SeqF3

2750 FER1_SeqF4

ATGCGTTCCCTGTTTCGAT

GTACAGCCTCCGCTCTCTTG

TGTCTGTGTCTCTCCCCAAA

Cloning of tub-DD-YFP-FER1 $\triangle T M /$ SagCAT

1651 FLPnOTM(NheI)_F GGTCCGCTAGCCCTGAAGAGGAAACCTACG

1652 FLPnoTM(XmaI)_R GGTCCCCCGGGTTACGTCCATTTCAGCCCACTCATAATGGC

Site Directed Mutagenesis of $C 2 D$

4833 SDM-FER1-1-2-F TCCGGCTCCCTACATCCAAGTGGAACTG

4834 SDM-FER1-1-2-R AACACGGCGTAGCCGACAGCTGGGAG

6His-FER1 for antiserum generation

2787 Ava-LIC-Fer1-F GGGTCCTGGTTCGATGTCGACGAAGGAAGGCAACATTC

2903 Ava-LIC-Fer1-R CTTGTTCGTGCTGTTTATTAGAGTTGCTCAGGCGTGAAGC

1404

Cloning of pmic3-MIC3-Cherry-DHFR

4864 gibpMIC3-MIC3-F GGAGATGACGAGACGTTTAAACGAGGAAAGTGGGGGGGGGGGG

4865 gibpMIC3-MIC3-R GTTATCCTCCTCGCCCTTGCTCACCCTAGGGAGACTCGCTGGGTACCTTCGTC 


\section{Supplementary Table S2. Description of plasmids used.}

1406

\begin{tabular}{|l|l|}
\hline Plasmid & Source and reference \\
\hline ptub-DD-YFP-FER1 $\Delta$ TM/sagCAT & In house [this paper] \\
\hline ptub-DD-Myc-FER1 $\Delta$ TM/sagCAT & In house [this paper] \\
\hline ptub-DD-Myc-FER1 $\Delta$ TM(D541A,D545A)/sagCAT & In house [this paper] \\
\hline ptub-DD-Myc-FER1 ${ }^{\text {FL/sagCAT }}$ & In house [this paper] \\
\hline ptub-DD-Myc-FER1 ${ }^{\text {FL }(D 541 A, D 545 A) / s a g C A T ~}$ & In house [this paper] \\
\hline ptub-YFP-TM ${ }^{\text {FER1/sagCAT }}$ & In house [this paper] \\
\hline ptub-IMC3-mCherryRFP/sagCAT & In house [95] \\
\hline pmic3-MIC3-mCherryRFP/hxgprtDHFR & In house [this paper] \\
\hline ptub-GRASP55-RFP/sagCAT & Graham Warren [105] \\
\hline Rab5A-HA OE Transient overexpression & Sabrina Marion [23] \\
\hline Rab7-HA OE Transient overexpression & Sabrina Marion [23] \\
\hline
\end{tabular}


1408 Supplementary Table S3. Description of antibody and antisera used.

\begin{tabular}{|l|l|l|l|l|}
\hline $\begin{array}{l}\text { Name } \\
\text { (monoclonal) }\end{array}$ & Species & $\begin{array}{l}\text { Dilution } \\
\text { (IFA) }\end{array}$ & $\begin{array}{l}\text { Dilution } \\
\text { (western) }\end{array}$ & Source and reference \\
\hline cMyc (9E10) & mouse & $1: 50$ & $1: 50$ & Santa Cruz Biotech \\
\hline HA (3F10) & mouse & $1: 3000$ & & Roche \\
\hline MIC2 (6D10) & mouse & $1: 2000$ & $1: 8000$ & David Sibley [106] \\
\hline MIC2 & rabbit & $1: 1000$ & $1: 8000$ & David Sibley [106] \\
\hline MIC3 & rabbit & $1: 100$ & $1: 400$ & Jean-François Dubremetz [107] \\
\hline MIC5 & rabbit & $1: 500$ & $1: 10000$ & Vern Carruthers [108] \\
\hline MIC8 & rabbit & $1: 1000$ & & Dominique Soldati [109] \\
\hline MIC10 & rabbit & $1: 500$ & $1: 15000$ & Vern Carruthers [110] \\
\hline M2AP & rabbit & $1: 1000$ & $1: 1000$ & Vern Carruthers [111] \\
\hline proM2AP & rabbit & $1: 1000$ & $1: 1000$ & Vern Carruthers [111] \\
\hline proMIC5 & rabbit & $1: 500$ & & Vern Carruthers [60] \\
\hline proROP4 & rabbit & $1: 750$ & & Gary Ward [112] \\
\hline GRA1 (TG17.43) & mouse & $1: 500$ & $1: 15000$ & BioVision.com [113] \\
\hline SAG1 (DG52) & mouse & $1: 500$ & & Jeroen Saeij [114] \\
\hline GRA3 (T62ch) & mouse & $1: 500$ & & $\begin{array}{l}\text { Maryse Lebrun, Jean-François } \\
\text { Dubremetz [115] }\end{array}$ \\
\hline SAG1 (T41E5) & $\begin{array}{l}\text { mouse \& } \\
\text { rabbit }\end{array}$ & $1: 500$ & & Jean-François Dubremetz [116] \\
\hline ROP2,3,4 & mouse & $1: 250$ & & Maryse Lebrun [117] \\
\hline DrpB & rat & $1: 2000$ & & Peter Bradley [50] \\
\hline VP1 & rabbit & $1: 4000$ & & Silvia Moreno [51] \\
\hline APH & rabbit & $1: 1000$ & & Dominique Soldati [28] \\
\hline IMC3 & rat & $1: 2000$ & $1: 1000$ & [95] \\
\hline hCentrin & rabbit & $1: 1000$ & & Iain Cheeseman, unpublished \\
\hline Tg- $\beta-t u b u l i n ~$ & $1: 500$ & & Naomi Morrissette [118] \\
\hline$\alpha-t u b u l i n ~(12 G 10)$ & mouse & $1: 2000$ & $1: 100$ & $\begin{array}{l}\text { Developmental Studies Hybridoma } \\
\text { Bank [119] }\end{array}$ \\
\hline NHE3 & guinea pig & $1: 1500$ & & Gustavo Arrizabalaga [54] \\
\hline FER1 & guinea pig & $1: 1000$ & $1: 1000$ & This paper \\
\hline & & & & \\
\hline
\end{tabular}

